\title{
Alloy Gene Gibbs Energy Partition Function and Equilibrium Holographic Network Phase Diagrams of AuCu-Type Sublattice System
}

\author{
Youqing Xie ${ }^{1,2,3^{*}}$, Xiaobo $\mathrm{Li}^{4}$, Xinbi Liu ${ }^{1,2,3}$, Yaozhuang Nie ${ }^{5}$, Hongjian Peng ${ }^{6}$ \\ ${ }^{1}$ School of Materials Science and Engineering, Central South University, Changsha, China \\ ${ }^{2}$ Powder Metallurgy Research Institute, Central South University, Changsha, China \\ ${ }^{3}$ State Key Laboratory of Powder Metallurgy, Central South University, Changsha, China \\ ${ }^{4}$ College of Mechanical Engineering, Xiangtan University, Xiangtan, China \\ ${ }^{5}$ School of Physical Science and Technique, Central South University, Changsha, China \\ ${ }^{6}$ School of Chemistry and Chemical Engineering, Central South University, Changsha, China \\ Email: *xieyouq8088@163.com
}

Received August 1, 2013; revised September 3, 2013; accepted September 14, 2013

Copyright (C) 2013 Youqing Xie et al. This is an open access article distributed under the Creative Commons Attribution License, which permits unrestricted use, distribution, and reproduction in any medium, provided the original work is properly cited.

\begin{abstract}
Taking AuCu-sublattice system as an example, we present two discoveries and a method. First, the alloy gene sequences are the central characteristic atom sequences in the basic coordination cluster sequences. Second, the transmission mode of the information about structures and properties of the alloy genes is described by the alloy gene Gibbs energy partition function. The most valuable method in the system sciences is "the whole obtained from a few parts". We have established the alloy gene database and holographic alloy positioning system of the $\mathrm{Au}-\mathrm{Cu}$ system, as well as alloy gene Gibbs energy partition function and equilibrium holographic network phase diagrams of the AuCu-type sublattice system. It means that a standard way for researchers to share predictive algorithms and computational methods may be produced during designing advanced alloys.
\end{abstract}

Keywords: Alloy Gene Gibbs Energy Partition Function; Holographic Alloy Positioning System; Equilibrium Holographic Network Phase Diagrams; Systematic Metal Materials Science; Au-Cu System

\section{Introduction}

There are 81 kinds of metal elements accounting for $79 \%$ in the Element Periodic Table, of which several alloy system groups can be composed: $C_{81}^{2}=3240$ kinds of binary alloy systems, $C_{81}^{3}=85320$ kinds of ternary alloy systems, $C_{81}^{4}=1663740$ kinds of quaternary alloy systems, and so on. In order to quickly and efficiently discover advanced alloys, we have to establish the Systematic Metal Materials Science (SMMS) by new thinking modes and methods of system sciences [1] (Supplementary Section 1).

"A diversity of structures of a system is attributed to combination and arrangement of structural units in the basic structure unit sequences". It is the first philosophic proposition of system sciences. Now, we deliver an extensive definition of the gene sequence: the gene sequence is a basic structure unit sequence carrying a set of

\footnotetext{
"Corresponding author.
}

transmission information about structures and properties for determining diversity of structures and properties of a system, which may be a biologic or non-biologic system. Therefore, it is our first task to seek alloy gene (AG) sequences for establishing the SMMS framework.

We have discovered that the AG-sequences are the central characteristic atom sequences in the basic coordination cluster sequences (Supplementary Figure S1(c)). In the fcc-based lattice $\mathrm{Au}-\mathrm{Cu}$ system, the basic coordination clusters $B_{i}^{\mathrm{Au}}=A_{i}^{\mathrm{Au}} \cdot[(I-i) \mathrm{Au}+i \mathrm{Cu}]$ and $B_{i}^{\mathrm{Cu}}=A_{i}^{\mathrm{Cu}} \cdot[(I-i) \mathrm{Au}+i \mathrm{Cu}]$ consist of the central characteristic atoms $A_{i}^{\mathrm{Au}}$ and $A_{i}^{\mathrm{Cu}}$ respectively, and the nearest coordinative configuration $[(I-i) \mathrm{Au}+i \mathrm{Cu}]$. Here, $I$ is the coordinative number and equal to $12 ; i$ is the number of $\mathrm{Cu}$-atoms and can change from 0 to 12; $(I-i)$ is the number of Au-atoms. Therefore, the AG-sequences of the $\mathrm{Au}-\mathrm{Cu}$ system are the central characteristic atom $A_{i}^{\mathrm{Au}}$ - and $A_{i}^{\mathrm{Cu}}$-sequences respectively in the $B_{i}^{\mathrm{Au}}$ - and $B_{i}^{\mathrm{Cu}}$-sequences. They may be used to replace 
atomic pair-sequence [2] and atomic cluster-sequences $[3,4]$, as well as other structural unit sequences [5-7] in the current alloy theories, because they have more analogous characters to biologic gene sequences: (1) The AG $A_{i}^{\mathrm{Au}}$ - and $A_{i}^{\mathrm{Cu}}$-sequences carry a set of transmission information: coordinative configurations, electronic structures, physical and thermodynamic properties, which have been obtained by the AG-theory (Supplementary Section 1). (2) Based on the AG-information, a Holographic Alloy Positioning (HAP) system of the $\mathrm{Au}-\mathrm{Cu}$ system has been established by "the Whole Obtained from a few Parts" (WOP) method (Section 2). (3) AGinformation may be transmitted to alloy phases by AGGibbs energy partition function (Section 3). The Equilibrium Holographic Network Phase (EHNP) diagrams of the AuCu-type sublattice system have been obtained by the HAP system (Section 4). (4) Alloy genes may be interconvertible, the essence of the order $\rightleftharpoons$ disorder transition can be explained by the AG-concentrations distributions (Figure 4). (5) Alloy genes will be used to design alloys, which may be called as the AG-arranging design.

\section{Holographic Alloy Positioning System}

The main objective of the HAP system of an alloy system is to provide a set of EHNP diagrams for designing advanced alloys. The HAP system of the $\mathrm{Au}-\mathrm{Cu}$ system consists of AG-theory, AG-Gibbs energy partition functions of $\mathrm{Au}_{3} \mathrm{Cu}-, \mathrm{AuCu}$ - and $\mathrm{AuCu}_{3}$-type sublattice systems and balance theory between sublattice systems (Figure 1). Its performing procedures are as follows: (1) The first step is to establish AG-database obtained by the AG-theory, only using experimental mixed enthalpies

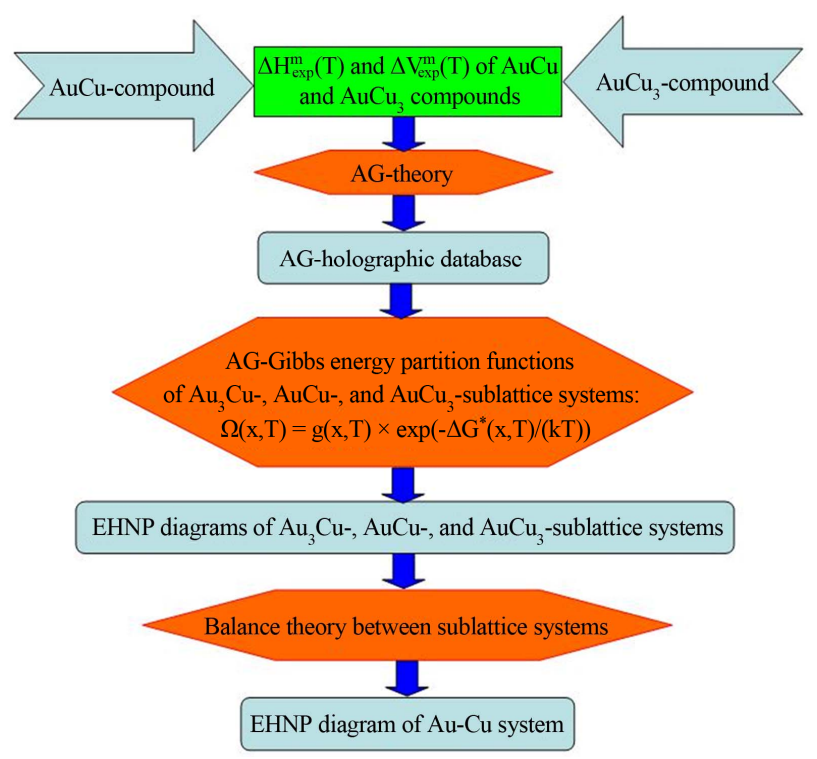

Figure 1. Holographic alloy positioning system of $\mathrm{Au}-\mathrm{Cu}$ system.
$\left(\Delta H_{\text {exp }}^{m}(T)\right)$ and mixed volumes $\left(\Delta V_{\exp }^{m}(T)\right)$ of the $\mathrm{AuCu}$ and $\mathrm{AuCu}_{3}$ compounds [8,9] (Supplementary Figures S2 and S5). (2) The second step is respectively to establish EHNP diagrams of the $\mathrm{Au}_{3} \mathrm{Cu}-\mathrm{AuCu}$ - and $\mathrm{AuCu}_{3}$-type sublattice systems, according to the AGGibbs energy partition functions of $\mathrm{Au}_{3} \mathrm{Cu}-, \mathrm{AuCu}-$ and $\mathrm{AuCu}_{3}$-type sublattice systems and the Bragg-Williams sublattice models $[10,11]$. (3) The third step is to establish EHNP diagrams of the $\mathrm{Au}-\mathrm{Cu}$ system based on the balance theory between sublattice systems. So much information is obtained by computing technique and a few experimental data, i.e., WOP method (Supplementary Section 1.5).

\section{AG-Gibbs Energy Partition Function}

"A diversity of properties of a system is attributed to contents and transmission mode of the information of basic structure unit sequences". It is the second philosophic proposition of system sciences. The transmission mode of AG-information is described by AG-Gibbs energy $\Omega(x, T)$-partition function, which consists of the AG-Gibbs energy transmission $G^{*}(x, T)$-function and AG-arranging structure $g\left(x_{i}^{\mathrm{Au}}(x, T), x_{i}^{\mathrm{Cu}}(x, T)\right)$-function (Supplementary Section 2).

An equilibrium order $\rightleftharpoons$ disorder transition of the AG-arranging structure of an alloy is defined as that "the AG-Gibbs energy levels $\left(G_{i}^{\mathrm{Au}}(T), G_{i}^{\mathrm{Cu}}(T)\right)$ and AGconcentrations $\left(x_{i}^{\mathrm{Au}}(x, T), x_{i}^{\mathrm{Cu}}(x, T)\right)$ occupied at the $G_{i}^{\mathrm{Au}}(T)$ - and $G_{i}^{\mathrm{Cu}}(T)$-energy levels can respond immediately and change synchronously with each small variation in temperature". It has following general behaviors: (1) The order $\rightarrow$ disorder transition upon heating and disorder $\rightarrow$ order transition upon cooling proceed along the same minimal mixed Gibbs energy $\Delta G_{\min }^{m}-T$ path, i.e., there exists no a so-called hysteresis phenomenon between both transitions. (2) The $\Delta G_{\min }^{m}-T$ path is continuous and has no jumping phenomenon.

\section{EHNP-Diagrams of AuCu-Type Sublattice System}

"Properties are determined by structures; properties should be suitable for environments; environments change structures". It is the fourth philosophic proposition of system sciences (the third one is presented in Supplementary Section 1.2). The man's knowledge of relationships of structures, properties and temperature for alloys has been changed from single causality to systematic correlativity, due to discoveries of alloy gene sequences and their information transmission mode, and establishments of the AG-Gibbs energy partition function and HAP system. This systematic correlativity may be described by a set of HNP diagrams.

An EHNP diagram consists of curves linked by the 
network $(q, x, T)$-points as functions of the state $q$, composition $\mathrm{x}$ and temperature $\mathrm{T}$. Each position inside the phase region and on the phase boundary $(\mathrm{PB})$ curve may be marked by the $(q, x, T)$-point, where the alloy state $\mathrm{q}$ denotes the AG-concentrations ( $x_{i}^{\mathrm{Au}}$ and $x_{i}^{\mathrm{Cu}}$ ), mixed Gibbs energy $\Delta G^{m}$, order degree $\sigma$, configurational entropy $S^{c}$, mixed characteristic Gibbs energy $\Delta G^{* m}$, mixed enthalpy $\Delta H^{m}$, mixed potential energy $\Delta E^{m}$, mixed volume $\Delta V^{m}$, generalized vibration free energy $X^{v}$, generalized vibration energy $U^{v}$, generalized vibration entropy $S^{v}$, mixed heat capacity $\Delta C_{p}^{m}$, mixed thermal expansion coefficient $\Delta \alpha^{m}$ and activities ( $a_{\mathrm{Au}}$ and $\left.a_{\mathrm{Cu}}\right)$. Each kind of the $q$-EHNP diagram includes four diagrams: three-dimension $q-x-T$ phase diagram, two-dimension $q_{x}-T, T_{q}-x$ and $q_{T}-x$ path phase diagrams. In the text the $\Delta G^{m}(x, T)$, $\sigma(x, T), S^{c}(x, T), x_{i}^{\mathrm{Au}}(x, T)$ and $x_{i}^{\mathrm{Cu}}(x, T)$ EHNP diagrams are presented. The other EHNP diagrams are shown in Supplementary Figure 6. The calculations of all diagrams are performed by compositional step $\Delta x=$ 0.5 at. $\%$ and temperature step $\Delta T=1 \mathrm{~K}$. These diagrams are interconnected. Therefore, a set of information about structures, properties and their variations with temperature of a designed alloy in the equilibrium state can be predicated by interlinking method and without calculation.

\subsection{Mixed Gibbs Energy and Order Degree EHNP Diagrams}

Using the minimal mixed Gibbs energy path method, we have obtained the three-dimension $\Delta G^{m}-x-T$ and $\sigma-x-T$ EHNP diagrams, and two-dimension $\Delta G_{x}^{m}-T, \sigma_{x}-T, T_{\Delta G^{m}}-x, T_{\sigma}-x, \Delta G_{T}^{m}-x$ and $\sigma_{T}-x$ path phase diagrams. From these diagrams, we have obtained following main understandings: (1) From Figures 2(a) and (a'), it can be known that there are ordered phase region (denoted by the symbol "O"), disordered phase region (denoted by the symbol "D"), $\mathrm{AuCu}$ compound consisted of $A_{8}^{\mathrm{Au}}$ and $A_{4}^{\mathrm{Cu}}$ genes (denoted by the symbol "C"), and the $\Delta G_{P B}^{m}(x, T)$ - and

$\sigma_{P B}(x, T)$-phase boundary curves in the each diagram. (2) From Figures 2(b) and (b'), it can be known that the $\mathrm{Au}_{47.5 \%} \mathrm{Cu}_{52.5 \%}$ alloy has the highest critical temperature $T_{c}=836 \mathrm{~K}$, which is higher than the critical temperature $(833 \mathrm{~K})$ of the $\mathrm{Au}_{50 \%} \mathrm{Cu}_{50 \%}$ alloy, that agrees with the experimental phenomenon (see Figure 2(c')). (3) From Figures 2(c) and (c'), it can be known that the phase diagrams can be respectively divided into the several regions by some $T_{\Delta G^{m}}-x$ and $T_{\sigma}-x$ curves. It is very useful to enrich the EHNP diagrams. (4) From Figure 2(c'), we have discovered that all experimental jumping temperatures $\left(T_{j}\right)$, which are denoted by symbols "*"[12] and " $\circ "$ [13], approach to the iso-order $T_{\sigma=0.65}-x$ curve. The experimental $T_{j}-x$ curve is very analogous to the equilibrium $T_{P B}-x$ curve, i.e., $T_{c}-x$ curve. However, the experimental jumping longrange order degree $\left(\sigma_{j}^{L R}\right)$ of the $\mathrm{AuCu}$ compound is about 0.8 , and the corresponding short-range order degrees $\left(\sigma^{S R}\right)$ is about 0.40 . These phenomena show that the experimental order $\rightarrow$ disorder transition belongs in metastable and non-equilibrium. (5) The isocompositional $\Delta G_{x}^{m}-T$ and $\sigma_{x}-T$ path diagrams (Figures 2(d) and (d')) will be used to establish EHNP diagrams of the $\mathrm{Au}-\mathrm{Cu}$ system.

\subsection{Configuration Entropy and AG- Concentration EHNP Diagrams}

The configuration entropy $\left(S^{c}(x, T)\right)$ and AG-concentration $\left(x_{i}^{\mathrm{Au}}(x, T), x_{i}^{\mathrm{Cu}}(x, T)\right)$ EHNP diagrams have been established, based on the AG-arranging structure $g\left(x_{i}^{\mathrm{Au}}(x, T), x_{i}^{\mathrm{Cu}}(x, T)\right)$-function in the $\Omega(x, T)$-function. From Figures 3 and $\mathbf{4}$, it can be known that each kind of q-EHNP diagram includes not only the 4-type diagrams indicated above, but also other-type diagrams. From Figure 3, we have obtained following main understandings: (1) The configuration entropy of each ordered alloy can change continually from the configuration entropy of the maximum order degree $\sigma_{\max }$ state to one of the ideal disordered state, that need not to induct any parameter. It means that we should take the ideal disordered state as the standard. (2) The structural units used for calculating configuration entropy should be in agreement with the structural units used for calculating corresponding energy levels. These are two rules to establish partition function. However, these rules are often neglected in the currently used thermodynamic models of alloy phases [14].

From Figure 4, we have obtained following main understandings: (1) The AG-concentration EHNP diagram may be described by two modes: the $x_{i}^{\mathrm{Au}}-x-T$ and $x_{i}^{\mathrm{Cu}}-x-T$ EHNP diagrams (Figures 4(a) and (a')) in the AG-arranging crystallography [15], where the $x_{i}^{\mathrm{Au}}$ and $x_{i}^{C u}$ are the probabilities occupied at the lattice points; the $x_{i}^{\mathrm{Au}}-x-i$ and $x_{i}^{\mathrm{Cu}}-x-i$ EHNP diagrams (Figures 4(a), (a'), (c) and (c')) in the AG-arranging band theory, where the $x_{i}^{\mathrm{Au}}$ and $x_{i}^{\mathrm{Cu}}$ are the probabilities occupied at the $G_{i}^{\mathrm{Au}}(T)$ and $G_{i}^{\mathrm{Cu}}(T)$ energy levels. (2) There exists a probability of AG-arranging structures in the alloy phases, which is described by the AGconcentration $\left(x_{i}^{\mathrm{Au}}(x, T), x_{i}^{\mathrm{Cu}}(x, T)\right)$ functions. This probability leads to atom-scale heterogeneity of properties of alloys. (3) There exists an emergent phenomenon of AG-arranging structures in the ordered alloy phases, which is defined as that some AG-concentrations of the alloy in ordered state are larger than one in the disordered state, such as $x_{9}^{\mathrm{Au}}, x_{8}^{\mathrm{Au}}, x_{7}^{\mathrm{Au}}, x_{3}^{\mathrm{Cu}}, x_{4}^{\mathrm{Cu}}$ and $x_{5}^{\mathrm{Cu}}$ (Figures 4(b)-(c')). (4) Alloy genes may be inter- 


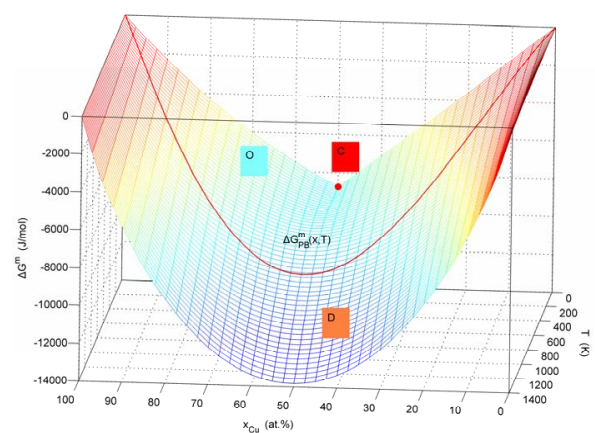

(a)

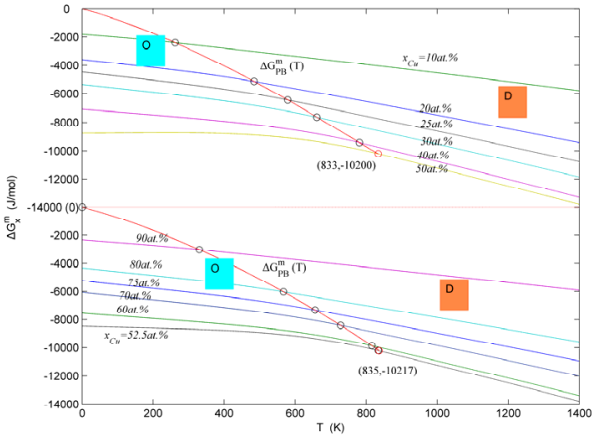

(b)

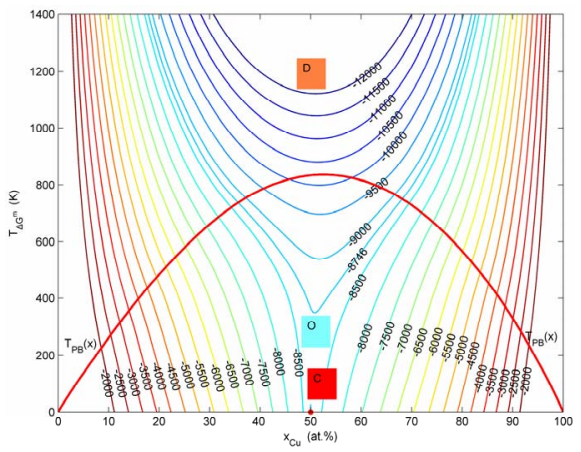

(c)

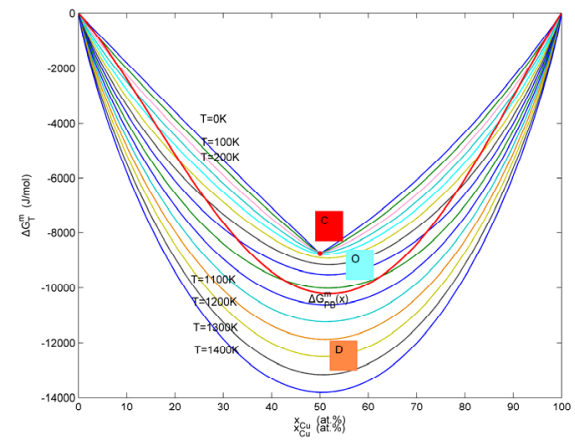

(d)

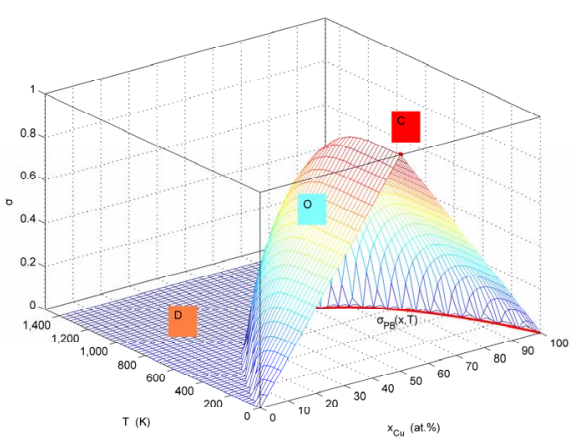

(a')

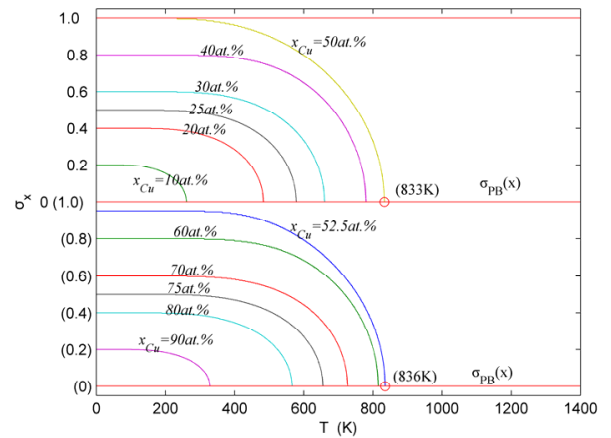

(b')

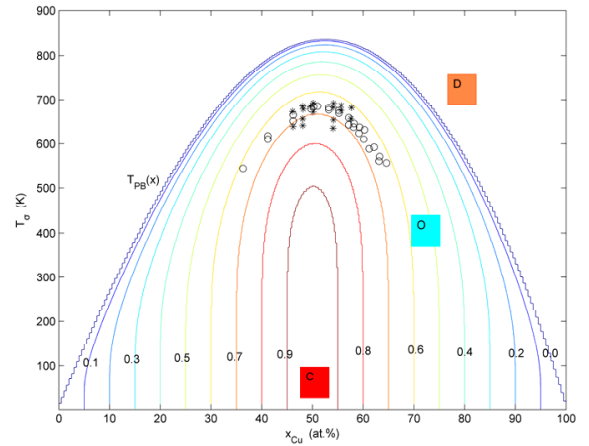

(c')

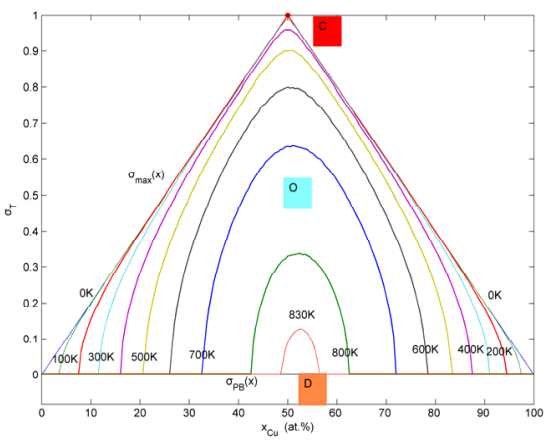

(d')

Figure 2. Mixed Gibbs energy and order degree EHNP diagrams. (a), (a'), Three-dimension $\Delta G^{m}-x-T$ and $\sigma-x-T$ diagrams with phase boundary curves $\Delta G_{P B}^{m}(x, T)$ and $\sigma_{P B}(x, T) ;(b)$, (b'), Two-dimension isocompositional $\Delta G_{x}^{m}-T$ and $\sigma_{x}-T$ path diagrams with phase boundary curves $\Delta G_{P B}^{m}(T)$ and $\sigma_{P B}(T) ;(c)$, (c'), Two-dimension iso-mixed Gibbs energy $T_{\Delta G^{m}}-x$ and iso-order degree $T_{\sigma}-x$ diagrams with phase boundary curves $T_{P B}(x)$; (d), (d'), Two-dimension isothermal $\Delta G_{T}^{m}-x$ and $\sigma_{T}-x$ diagrams with phase boundary curves $\Delta G_{P B}^{m}(x)$ and $\sigma_{P B}(x)$. 


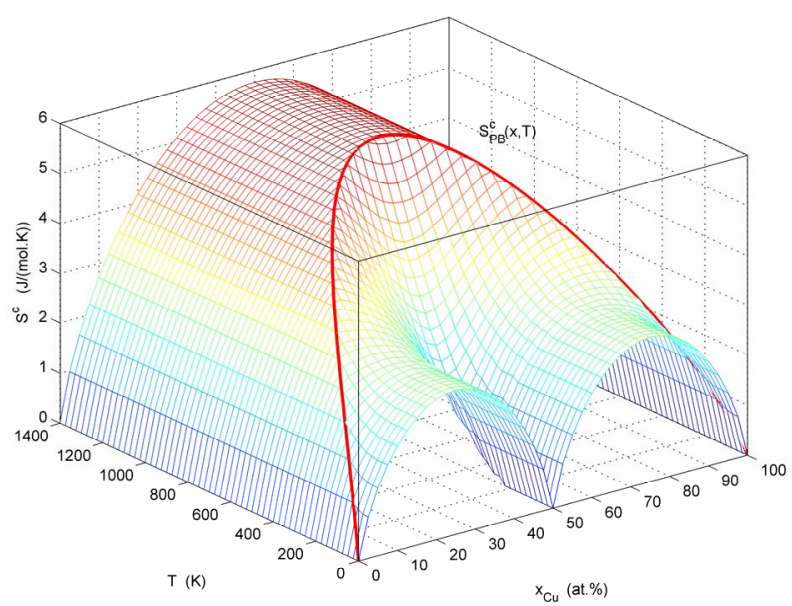

(a)

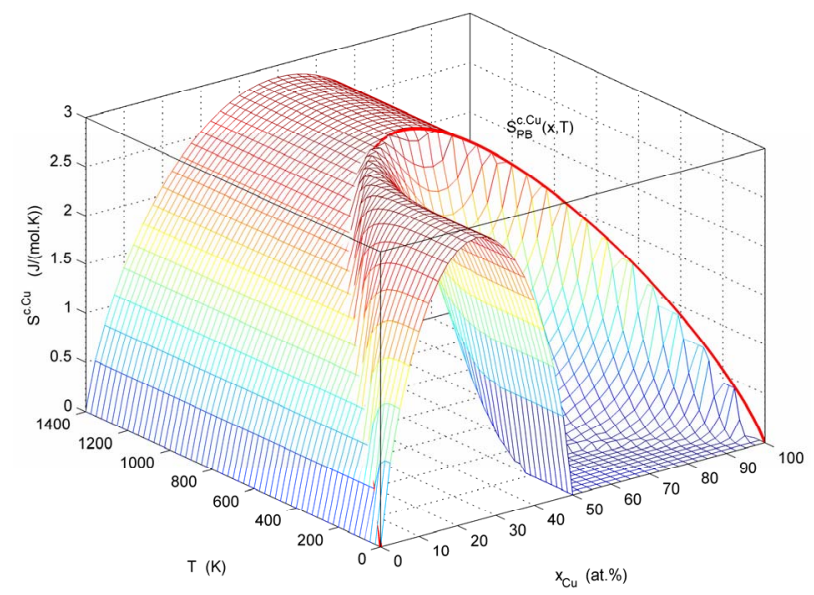

(c)

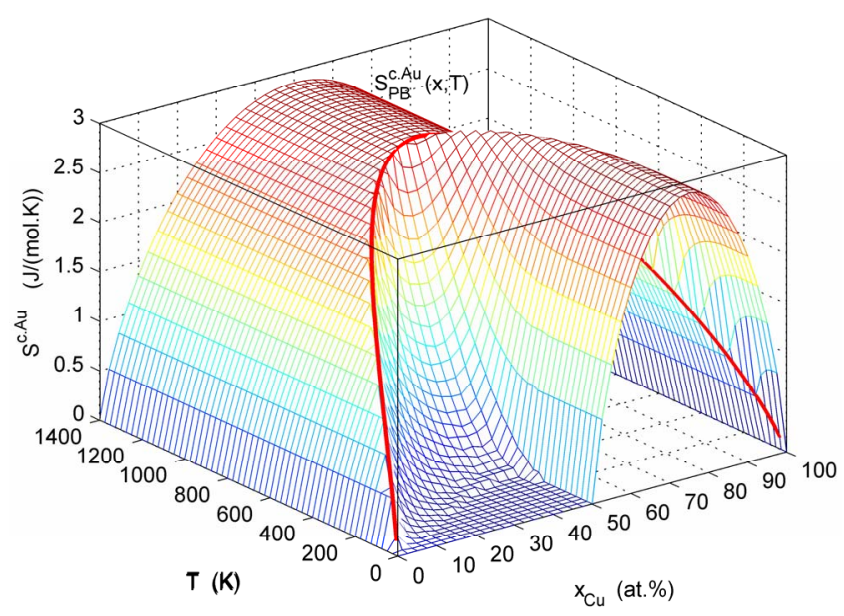

(b)

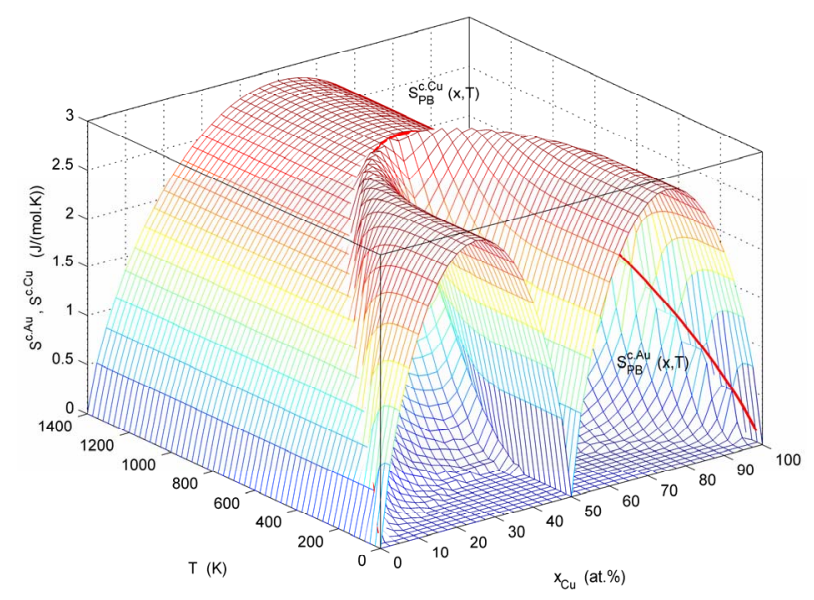

(d)

Figure 3. Configuration entropy EHNP diagrams of the AuCu-type sublattice system. a) Three-dimension $S^{c}-x-T$ phase diagram with phase boundary curve $S_{P B}^{c}(x, T)$; b) Three-dimension $S^{c . A u}-x-T$ phase diagram with phase boundary curve $S_{P B}^{c . A u}(x, T)$ of the Au-component; c) Three-dimension $S^{c . C u}-x-T$ diagram with phase boundary curve $S_{P B}^{c . C u}(x, T)$ of the Cu-component; d) Three-dimension $\left(S^{c . A u}, S^{c . C u}\right)-x-T$ combinational phase diagrams with phase boundary curves $S_{P B}^{c . A u}(x, T)$ and $S_{P B}^{c . C u}(x, T)$ of the Au- and Cu-components.

convertible. The essence of the order $\rightarrow$ disorder transition of the stoichiometric $\mathrm{AuCu}$ compound consisting of $A_{8}^{\mathrm{Au}}$ - and $A_{4}^{\mathrm{Cu}}$-alloy genes is that the $A_{8}^{\mathrm{Au}}$ - and $A_{4}^{\mathrm{Cu}}$-alloy genes are split into the $A_{i}^{\mathrm{Au}}$ - and $A_{i}^{\mathrm{Cu}}$-sequences, respectively; otherwise the essence of the disorder $\rightarrow$ order transition of the stoichiometric disordered $\mathrm{AuCu}$ alloy is that the $A_{i}^{\mathrm{Au}}$ - and $A_{i}^{\mathrm{Cu}}$-sequences are degenerated into the $A_{8}^{\mathrm{Au}}$ - and $A_{4}^{\mathrm{Cu}}$-alloy genes (Figures $\mathbf{4 ( d )}$ and (d')).

\section{Conclusions}

In this paper, these creative achievements are of broad significances: (1) Four philosophic propositions of system sciences will prove stimulating to researchers work- ing on general system sciences, matter systems and social systems, and who may well find value in using them as a philosophic thinking logic for establishing various system science frameworks. (2) the AG-sequence instead of compositional atoms, compositional atom pairs and compositional atom clusters sucessively proposed during last one hundred years will prove stimulating to researchers working on physics, chemistry and material science, and who may well find value in using it as basic structure unit sequence for establish SMMS framework. (3) The AG-Gibbs energy partition function composed of AG-Gibbs energy level model of chemical potential and AG-statistic model of entropy replaces two current functions: one is composed of atom pair energy level model 

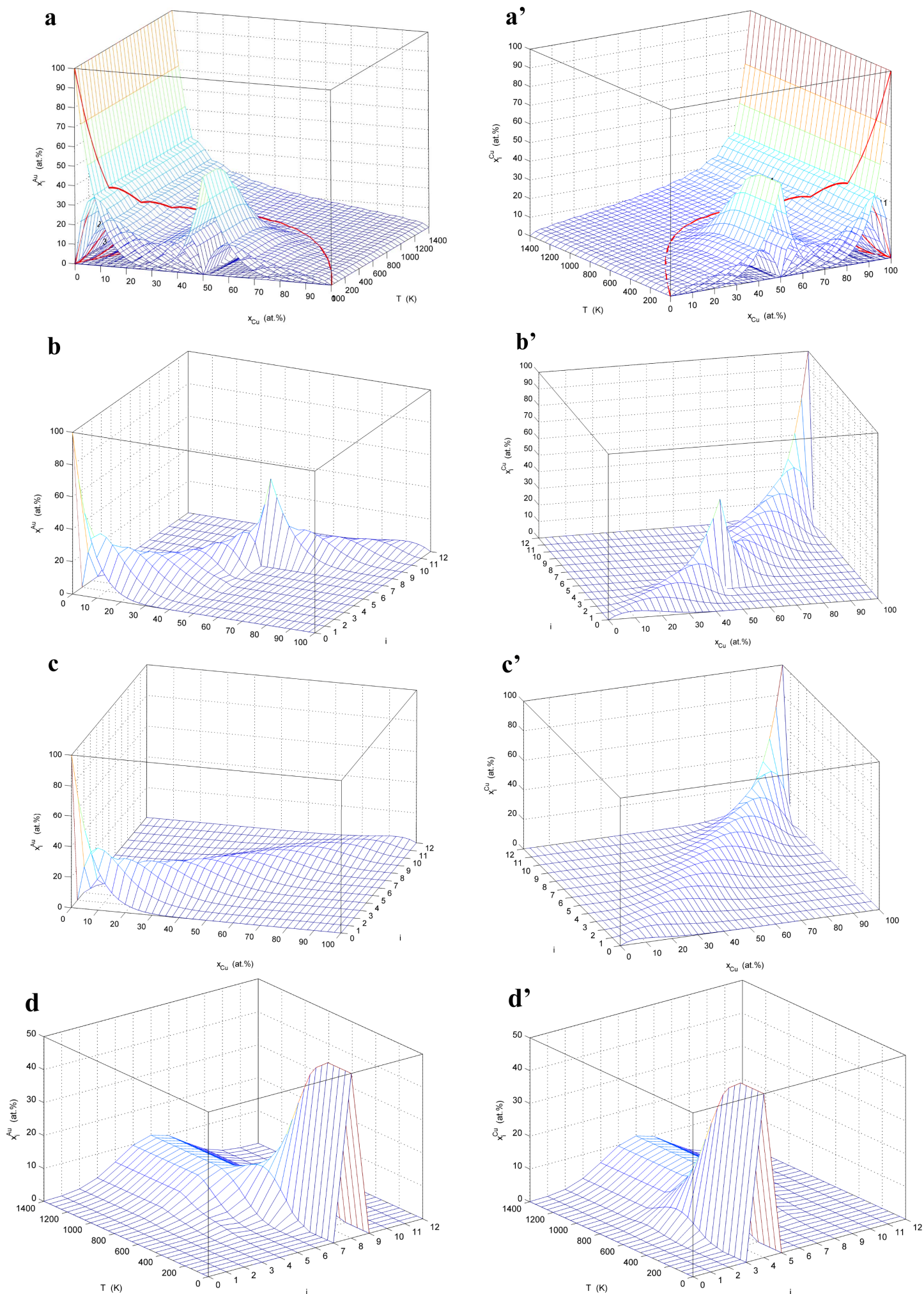

Figure 4. AG-concentration EHNP diagrams. (a), (a'), Three-dimension $x_{i}^{\mathrm{Au}}-x-T$ and $x_{i}^{\mathrm{Cu}}-x-T$ diagrams; (b), (b'), Three-dimension $x_{i}^{\mathrm{Au}}-x-i$ and $x_{i}^{\mathrm{Cu}}-x-i$ diagrams of the ordered $\mathrm{Au}_{(1-x)} \mathrm{Cu}_{x}$ alloys with maximum order degree $\sigma_{\max }$ at $0 \mathrm{~K}$; (c), (c'), Three-dimension $x_{i}^{\mathrm{Au}}-x-i$ and $x_{i}^{\mathrm{Cu}}-x-i$ diagrams of the perfectly disordered $\mathrm{Au}_{(1-x)} \mathrm{Cu}_{x}$ alloys; (d), (d'), Three-dimension $x_{i}^{\mathrm{Au}}-T-i$ and $x_{i}^{\mathrm{Cu}}-T-i$ path diagrams of disordering for the stoichiometric AuCu compound. 
of chemical potential and compositional atom statistic model of entropy; another one is composed of electron energy level model of chemical potential and compositional atom cluster model of entropy. That will prove stimulating to researchers working on physics, chemistry and materials science, and who may well find value in using it as a theoretic foundation for establishing alloy system sciences of binary and ternary alloy systems. (4) The HAP system based on the AG-Gibbs energy partition function and the WOP method will prove stimulating to researchers working on physics, chemistry and materials science, and who may well find value in using it as a platform for establishing EHNP diagrams of alloy systems. (5) The great holographic alloy database consisting of AG-database and EHNP diagrams of alloy systems will prove stimulating to others working on materials engineering, and who may well find value in using it as a tool for materials discovery, design, manufacture and application, which may be called as "AG-Arranging (AGA) Engineering". The investigation in AuCu-type sublattice system may be analogous to Mendel's investigation in genetic characters of peas.

\section{Acknowledgements}

The work was supported by the National Natural Science Foundation of China (51071181); and by the Natural Science Foundation of Hunan province (2012FJ4044), China.

\section{REFERENCES}

[1] Y. Q. Xie, "Systematic Science of Alloys," Central South University Press, Changsha, China, 2012.

[2] H. A. Bethe, "Statistical Theory of Superlattices," Proceedings of the Royal Society of London, Vol. 150, No. 871, 1935, pp. 552-575.

http://dx.doi.org/10.1098/rspa.1935.0122

[3] R. Kikuchi, D. De Fontaine, M. Murakami and T. Nakamura, "Ternary Phase Diagram Calculations-II Examples of Clustering and Ordering Systems," Acta Metallurgica, Vol. 25, 1997, pp. 207-219. http://dx.doi.org/10.1016/0001-6160(77)90124-9

[4] M. Asta and D. De Fontaine, "First-Principles Study of Phase Stability of Ti-Al Intermetallic Compounds," Journal of Materials Research, Vol. 8, No. 10, 1993, pp. 2554-2568. http://dx.doi.org/10.1557/JMR.1993.2554

[5] V. Ozolins, C. Wolverton and A. Zunger, "Cu-Au, Ag-Au, $\mathrm{Cu}-\mathrm{Ag}$, and $\mathrm{Ni}-\mathrm{Au}$ Intermetallics: First-Principles Study of Temperature-Composition Phase Diagrams and Structures," Physical Review B, Vol. 57, No. 11, 1998, pp. 6427-6443. http://dx.doi.org/10.1103/PhysRevB.57.6427

[6] B. Sundman, S. G. Fries and W. A. Oates, "A Thermodynamic Assessment of the Au-Cu System," Calphad, Vol. 22, No. 2, 1998, pp. 335-354.

http://dx.doi.org/10.1016/S0364-5916(98)00034-0
[7] Hillert, M., "The compound energy formalism," Journal of Alloys and Compounds, Vol. 320, No. 2, 2001, pp. 161-176.

http://dx.doi.org/10.1016/S0925-8388(00)01481-X

[8] Y. Q. Xie, X. B. Liu, X. B. Li, H. J. Peng and Y. Z. Nie, "Potential Energies of Characteristic Atoms on Basis of Experimental Heats of Formation of $\mathrm{AuCu}$ and $\mathrm{AuCu} 3$ Compounds," Transactions of Nonferrous Metals Society of China, Vol. 19, No. 5, 2009, pp.1243-1256. http://dx.doi.org/10.1016/S1003-6326(08)60436-7

[9] Y. Q. Xie, X. B. Liu, X. B. Li, H. J. Peng and Y. Z. Nie, "Volume Sequences of Characteristic Atoms Separated from Experimental Volumes of $\mathrm{AuCu}$ and $\mathrm{AuCu}_{3} \mathrm{Com}$ pounds," Transactions of Nonferrous Metals Society of China, Vol. 19, No. 6, 2009, pp. 1559-1617. http://dx.doi.org/10.1016/S1003-6326(09)60077-7

[10] W. L. Bragg and E. J. Williams, "The Effect of Thermal Agitation on Atomic Arrangement in Alloys," Proceedings the Royal of Society A, Vol. 145, No. 855, 1934, pp. 699-730. http://dx.doi.org/10.1098/rspa.1934.0132

[11] W. L. Bragg and E. J. Williams, "The Effect of Thermal Agitation on Atomic Arrangement in Alloys II," Proceedings the Royal of Society A, Vol. 151, No. 874, 1935, pp. 540-566. http://dx.doi.org/10.1098/rspa.1935.0165

[12] R. A. Oriani, "Thermodynamics of Order Alloy. II. The Gold-Copper System," Acta Metallurgica, Vol. 2, No. 4, 1954 , pp. 608-615.

http://dx.doi.org/10.1016/0001-6160(54)90196-0

[13] F. N. Rhines, W. E. Bond and R. A. Rummel, "Constitution of Order Alloys of the System Copper-Gold," Transactions of the American Society of Metals, Vol. 47, 1955, pp. 578-597.

[14] W. A. Oates, F. Zhang, S.-L .Chen and Y.A. Chang, "Improved Cluster-Site Approximation for the Entropy of Mixing in Multicomponent Solid Solutions," Physical Review B, Vol. 59, No. 17, 1999, pp. 11221-11225. http://dx.doi.org/10.1103/PhysRevB.59.11221

[15] Y. Q. Xie, X. B. Liu, H. J. Peng, Y. Z. Nie, X. B. Li and Y. F. Li, "Characteristic Atom Arranging Crystallography of Alloy Phases for Au-Cu System," Science China: Technological Sciences, Vol. 54, No. 6, 2011, pp. 15601567. http://dx.doi.org/10.1007/s11431-011-4390-4

[16] Y. Q. Xie, “Atomic Energies and Gibbs Energy Functions of Ag-Cu Alloys," Science in China (Series E), Vol. 41, No. 2, 1998, pp. 146-156.

http://dx.doi.org/10.1007/BF02919677

[17] Y. Q. Xie and X. D. Zhang, "Atomic Volume and Volume Functions of Ag-Cu Alloys," Science in China (Series $E$ ), Vol. 41, No. 2, 1998, pp. 157-168. http://dx.doi.org/10.1007/BF02919678

[18] Y. Q. Xie, “A New Potential Function with Many-Atom Interactions in Solid," Science in China (Series A), Vol. 36, No.1, 1993, pp. 90-99.

[19] Y. Q. Xie, "Electronic Structure and Properties of Pure Iron," Acta Metallurgica et Materialia, Vol. 42, No. 11, 1994, pp. 3705-3715. http://dx.doi.org/10.1016/0956-7151(94)90436-7

[20] Y. Q. Xie, "Relationship between Partial and Average 
Atomic Volumes of Components in Au-Ni Alloys",

Transactions of Nonferrous Metals Society of China, Vol.
21, No. 8, 2011, pp. 1801-1807.

http://dx.doi.org/10.1016/S1003-6326(11)60934-5 


\section{Supplementary Information}

\section{Alloy Gene (AG) Theory of Au-Cu System}

\subsection{New Thinking Modes of System Sciences}

'A diversity of structures of a system is attributed to combination and arrangement of structure units in the basic structure unit sequence'. It is the first philosophic proposition of system sciences proposed by us. For examples, the diversity of species in the biological system is attributed to splices of some biological genes in the biological gene sequences; the diversity of free atom states in the free atom system is attributed to arrangement of electrons in the electronic orbital (state) sequence described by four quantum numbers; the diversity of crystalline species in the geometric crystallography is attributed to combination of symmetric elements in the symmetric element sequence; the diversity of music scores in the music system is attributed to combination and arrangement of notes in the music note sequence, and so on. This philosophic proposition guides us to seek the most important structure units for designing advanced alloys. They are the central characteristic atoms in the basic coordination clusters, and called as alloy genes (AG).

"A diversity of properties of a system is attributed to the contents and transmission mode of the information of the basic structure unit sequences". It is the second philosophic proposition of system sciences proposed by us. It is also essential condition to establish a systematic science theory of a certain system. It is a protracted and tortuous history to research structures, properties, evolutions and functions of the biologic gene sequences for establishing biosystematics. It is another good example to research structures, properties, evolutions and functions of electronic state sequences for establishing systematic science of free atom system. Through a longterm exploring we have proposed a fictitious structure unit (Supplementary Section 1.3), which is the characteristic crystal consisted of the same alloy genes with known potential energy and volume, and with the same based lattice to the alloy system. Then, we have established the valence bond theory and thermodynamics of characteristic crystals. By both these theories, we can calculate the valence electron structures of characteristic crystals, which may represent ones of alloy genes, and the physical and thermodynamic properties of characteristic crystals, which may represent contributions of alloy genes to properties of alloys. Now, we have discovered that the transmission mode of the AG-in-formation about structures and properties can be described by the AG-Gibbs energy partition function.

\subsection{Structural Levels of Alloy Systems}

"The complexity and entirety of a complex system are attributed to the multilevel of the structures and properties and to the various correlatives between different structural levels, between different properties and between the structures and properties." It is the third philosophic proposition of system sciences proposed by us.

The SMMS framework contains three levels: the electron-structures of atoms, atom- and electron (valence bond)-structures of phases and phase-structures of organizations (Supplementary Figure S1(a)), which are simplified as atom-, phase- and organization-levels, respectively. The traditional crystallography and thermodynamics of alloys contain phase-level and organizationlevel. The first-principles electron theory of alloys belongs in the electron-structures of phases (Supplementary Figure S1(b)). Therefore, traditional alloy theories have no atom-level theory, i.e., AG-theory.

\subsection{Structural Unit Sequences of the Au-Cu Al- loy System}

In order to explain diversities of structures and properties of alloy phases, we proposed three structural unit sequences.

Basic coordination cluster B-sequences:

$B_{0}^{\mathrm{Au}} \cdots B_{i}^{\mathrm{Au}} \cdots A_{12}^{\mathrm{Au}} ; B_{0}^{\mathrm{Cu}} \cdots B_{i}^{\mathrm{Cu}} \cdots B_{12}^{\mathrm{Cu}}$. They are formed by the central characteristic atoms $\left(A_{i}^{\mathrm{Au}}, A_{i}^{\mathrm{Cu}}\right)$ and the nearest coordinative configuration $[(12-i) A u+i C u]$. The alloy phase is formed by the Basic Coordination Cluster Overlapping (Simplified as BCO model) (Supplementary Figure S1(c)).

Alloy genes A-sequences: $A_{0}^{\mathrm{Au}} \cdots A_{i}^{\mathrm{Au}} \cdots A_{12}^{\mathrm{Au}}$; $A_{0}^{\mathrm{Cu}} \cdots A_{i}^{\mathrm{Cu}} \cdots A_{12}^{\mathrm{Cu}}$. They are the central characteristic atoms of basic coordination clusters. The alloy phase is formed by the Alloy Gene Arranging (Simplified as AGA model) (Supplementary Figure S1(c)).

Characteristic crystal C-sequences: $C_{0}^{\mathrm{Au}} \cdots C_{i}^{\mathrm{Au}} \cdots C_{12}^{\mathrm{Au}}$; $C_{0}^{\mathrm{Cu}} \cdots C_{i}^{\mathrm{Cu}} \cdots C_{12}^{\mathrm{Cu}}$. Each fictitious characteristic crystal consists of the same characteristic atoms. The alloy phase is formed by the Characteristic Crystal Mixing (Simplified as CCM model) (see Supplementary Figure S1(d), Supplementary Section 1.6).

Recently, we have discovered that the alloy gene sequences are very useful to design advanced alloys.

\subsection{The Separated Theory of Potential Energies and Volumes of Alloy Genes}

The AG-theory consists of three parts (Supplementary Figure S2(a)): separated theory of potential energies and volumes of alloy genes [16,17], valence bond theory $[18,19]$ and thermodynamics of characteristic crystals (see Equations (9) to (24)).

The extensive properties $q(x, T), q_{A}(x, T)$, $q_{B}(x, T)$ functions of a given alloy phase and its components can be obtained by a transmission law of the 
$\mathbf{a}$

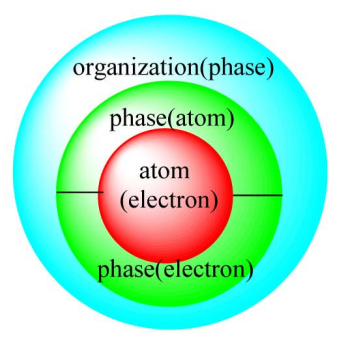

b

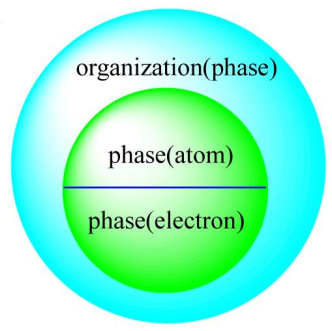

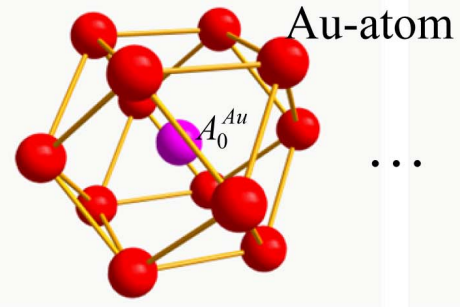

$B_{0}^{A u}$

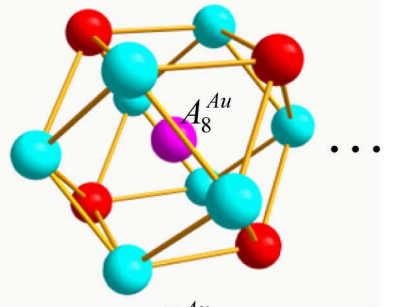

$B_{8}^{A u}$

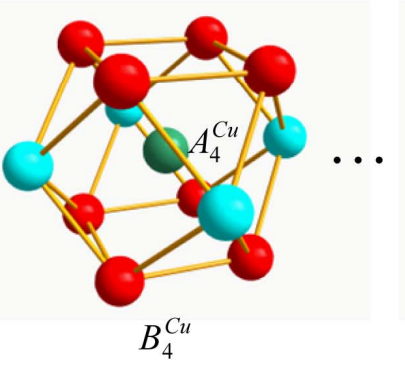

$B_{0}^{C u}$

d

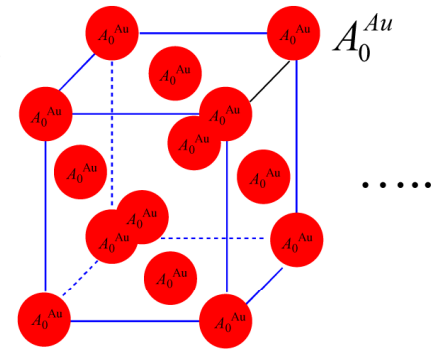

$C_{0}^{A u}$

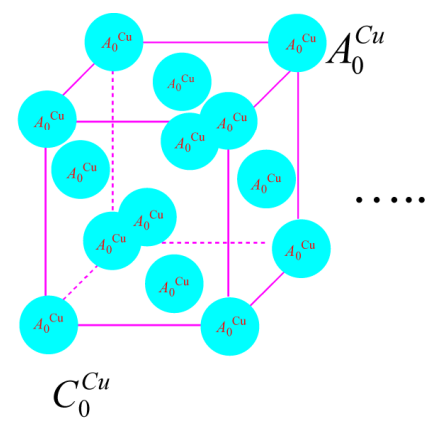

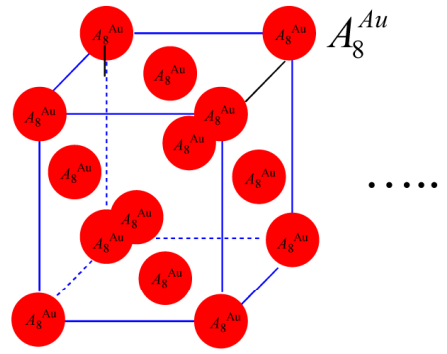

$C_{8}^{A u}$

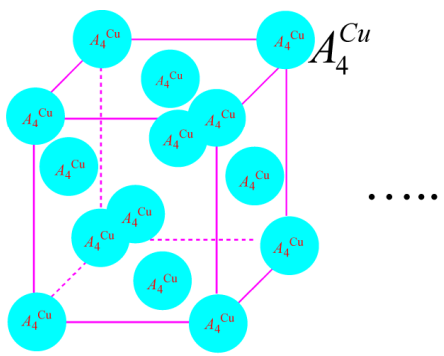

$C_{4}^{C u}$

\section{c}

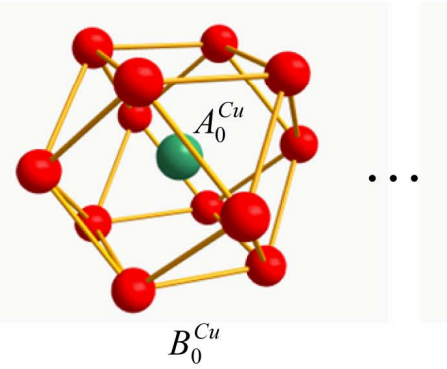

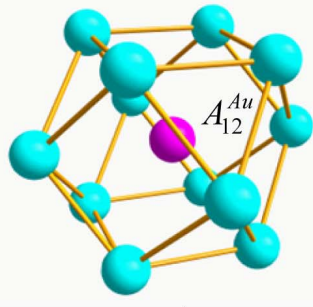

$B_{12}^{A u}$
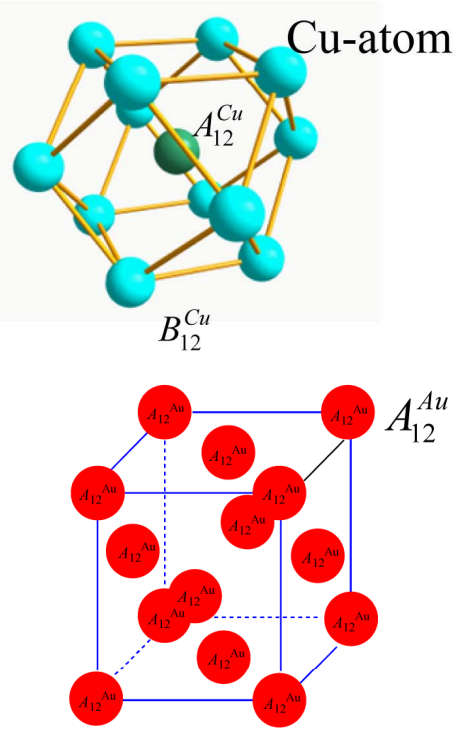

$C_{12}^{A u}$

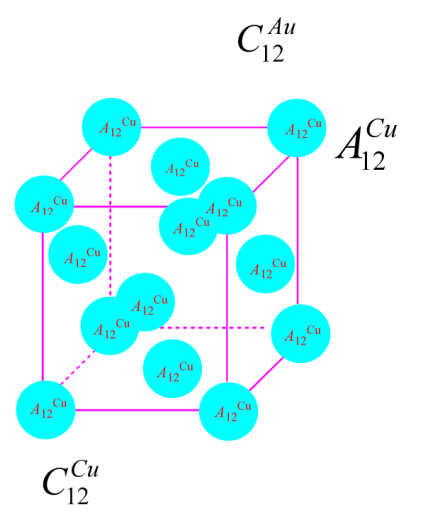

Figure S1. Theoretic levels and three structural unit sequences. a) Theoretic levels in SMMS framework; b) Theoretic levels in the traditional alloy theory; c) Basic coordination cluster sequences and AG-sequences: $B_{0}^{\mathrm{Au}} \cdots B_{8}^{\mathrm{Au}} \cdots B_{12}^{\mathrm{Au}}$,

$B_{12}^{\mathrm{Cu}} \cdots B_{4}^{\mathrm{Cu}} \cdots B_{0}^{\mathrm{Cu}}$ and $A_{0}^{\mathrm{Au}} \cdots A_{8}^{\mathrm{Au}} \cdots A_{12}^{\mathrm{Au}}, A_{12}^{\mathrm{Cu}} \cdots A_{4}^{\mathrm{Cu}} \cdots A_{0}^{\mathrm{Cu}}$; d) The characteristic crystal-sequences: $C_{0}^{\mathrm{Au}} \cdots C_{8}^{\mathrm{Au}} \cdots C_{12}^{\mathrm{Au}}$, $C_{12}^{\mathrm{Cu}} \cdots C_{4}^{\mathrm{Cu}} \cdots C_{0}^{\mathrm{Cu}}$. 

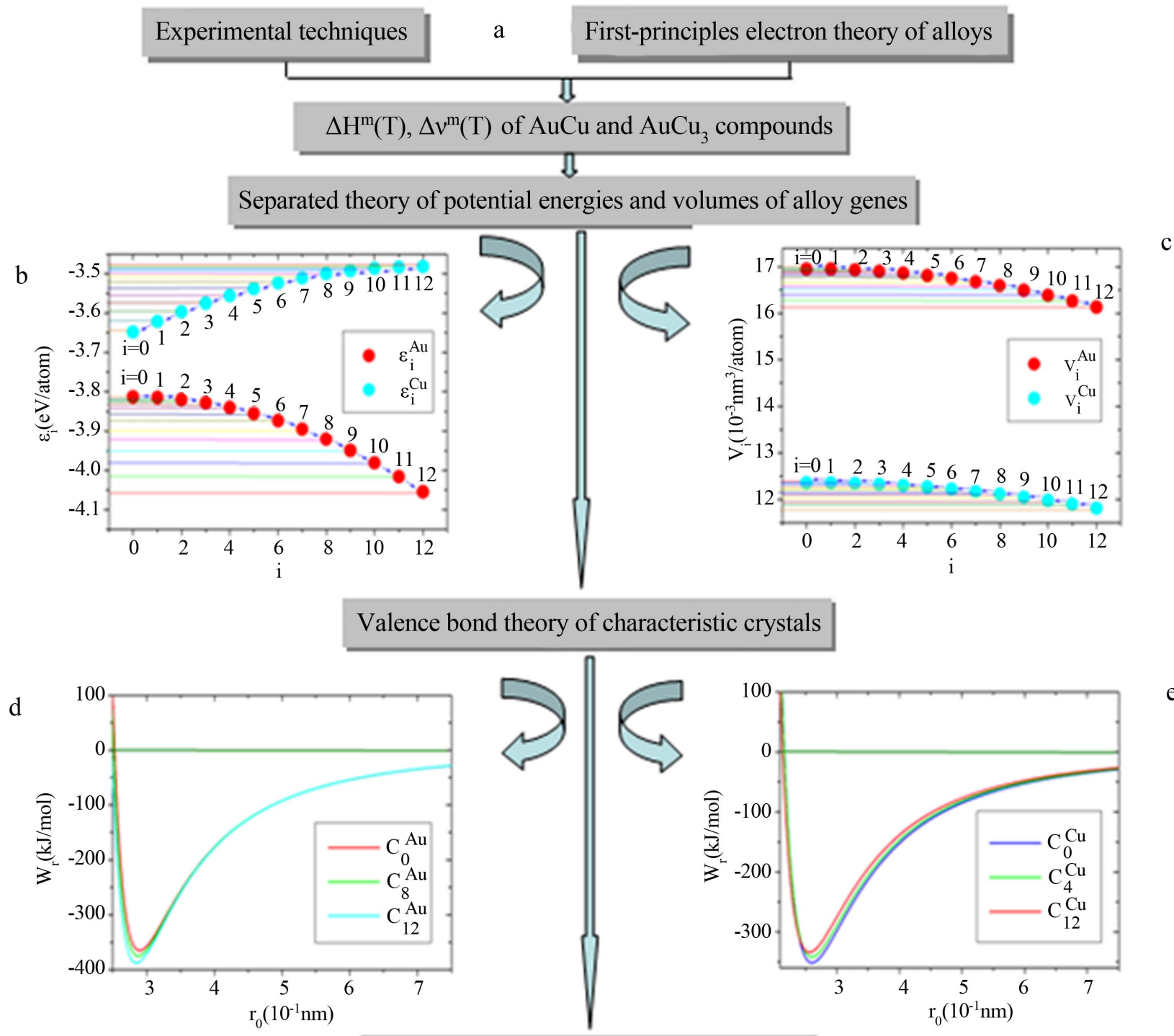

Thermodynamics of characteristic crystals
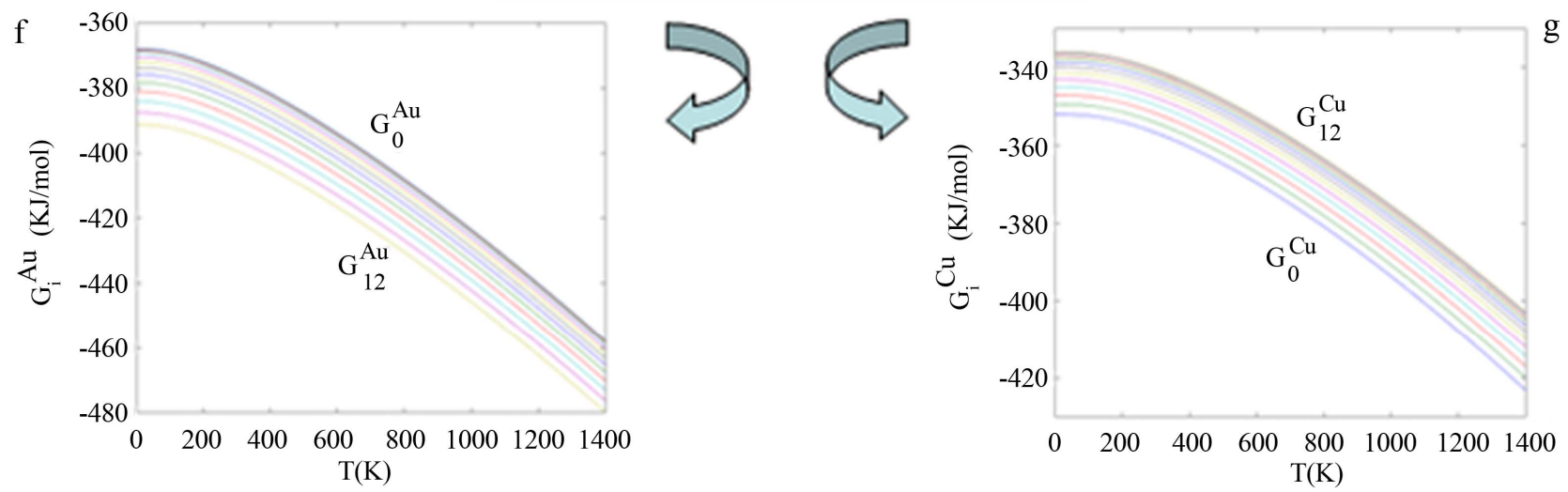

Figure S2. AG-theory and AG-properties. a) AG-theory based on the experimental techniques or the first-principles electron theory of alloys; b), c) AG-potential energies $\varepsilon_{i}^{\mathrm{Au}}$ - and $\varepsilon_{i}^{\mathrm{Cu}}$-sequences, $v_{i}^{\mathrm{Au}}$-and $v_{i}^{\mathrm{Cu}}$-sequences; d), e) Potential energy curves of alloy genes: $\left.\left.W_{0}^{\mathrm{Au}}(r) \cdots W_{8}^{\mathrm{Au}}(r) \cdots W_{12}^{\mathrm{Au}}(r), W_{12}^{\mathrm{Cu}}(r) \cdots W_{4}^{\mathrm{Cu}}(r) \cdots W_{0}^{\mathrm{Cu}}(r) ; \mathbf{f}\right), \mathrm{g}\right)$ Gibbs energy curves: $G_{0}^{\mathrm{Au}}(T) \cdots G_{8}^{\mathrm{Au}}(T) \cdots G_{12}^{\mathrm{Au}}(T), G_{12}^{\mathrm{Cu}}(T) \cdots G_{i}^{\mathrm{Cu}}(T) \cdots G_{0}^{\mathrm{Cu}}(T)$. 
extensive q-properties of alloy genes, which may be simplified as AGT law:

$$
\left\{\begin{array}{l}
q(x, T)=\sum_{i=0}^{I} x_{i}^{A}(x, T) q_{i}^{A}(T)+\sum_{i=0}^{I} x_{i}^{B}(x, T) q_{i}^{B}(T) \\
q_{A}(x, T)=\sum_{i=0}^{I} x_{i}^{A}(x, T) q_{i}^{A}(T) / x_{A} \\
q_{B}(x, T)=\sum_{i=0}^{I} x_{i}^{B}(x, T) q_{i}^{B}(T) / x_{B}
\end{array}\right.
$$

where, the $q$ denotes potential energy $(E)$ and volume $(v)$, which are the functions as temperature $(T)$; the $x_{i}^{A}(x, T)$ and $x_{i}^{B}(x, T)$ are the concentrations of the alloy genes; which are the functions of the composition $(x)$ and temperature $(T) ; \quad x_{A}$ and $x_{B}$ denote compositions of the $A$ and $B$ components, respectively.

In order to make the Equation (1) become the simple, applicable and separable $q(x, T, \sigma)$ function, three type relations of $q_{i}^{A}$ and $q_{i}^{B}$ with $i$ have been designed:

(i)Type I of linear relation,

$$
\left\{\begin{array}{l}
q_{i}^{A}=q_{0}^{A}+(i / I)\left(q_{I}^{A}-q_{0}^{A}\right) \\
q_{i}^{B}=q_{I}^{B}+[(I-i) / I]\left(q_{0}^{B}-q_{I}^{B}\right)
\end{array}\right.
$$

(ii)Type II of concave parabola relation,

$$
\left\{\begin{array}{l}
q_{i}^{A}=q_{0}^{A}+(q / I)^{2}\left(q_{I}^{A}-q_{0}^{A}\right) \\
q_{i}^{B}=q_{I}^{B}+[(I-i) / I]^{2}\left(q_{0}^{B}-q_{I}^{B}\right)
\end{array}\right.
$$

(iii)Type III of convex parabola relation,

$$
\left\{\begin{aligned}
q_{i}^{A}= & q_{0}^{A}+(2 i / I)\left(q_{I}^{A}-q_{0}^{A}\right)-(i / I)^{2}\left(q_{I}^{A}-q_{0}^{A}\right) \\
q_{i}^{B}= & q_{I}^{B}+[2(I-i) / I]\left(q_{0}^{B}-q_{I}^{B}\right) \\
& -[(I-i) / I]^{2}\left(q_{0}^{B}-q_{I}^{B}\right)
\end{aligned}\right.
$$

where, the $q_{0}^{A}$ and $q_{I}^{B}$ denote, respectively, $q$-properties of the primary state alloy genes; the $q_{I}^{A}$ and $q_{0}^{B}$ denote, respectively, $q$-properties of the terminal state alloy genes.

By combining Equations (2)-(4) and substituting them into Equation (1), nine $q(x, T)$ functions can be obtained. In Supplementary Table S1 the nine general $q(x, T)$-functions of alloy phases can be used to compounds, ordered and disordered alloy phases. In Supplementary Table S2, the nine $q(x, T)$-functions can be used for the disordered alloy phases only.

\subsection{Methodology}

The most valuable method in the systematic science is "the whole obtained from a few parts", which may be simplified as the WOP method. It means that a system can be reproduced from it's a few parts. Such as the whole of a tree can be reproduced from a seed, a branch

\begin{tabular}{|c|c|c|}
\hline No. & $\begin{array}{l}\text { Type } \\
\text { A B }\end{array}$ & Functions \\
\hline 1 & I I & $q(x, T)=x_{A} q_{0}^{A}(T)+x_{B} q_{I}^{B}(T)+\sum_{i=0}^{I}\left(\frac{i}{I} x_{i}^{A}\right)\left(q_{I}^{A}(T)-q_{0}^{A}(T)\right)+\sum_{i=0}^{I}\left(\frac{I-i}{I} x_{i}^{B}\right)\left(q_{0}^{B}(T)-q_{I}^{B}(T)\right)$ \\
\hline 2 & I II & $q(x, T)=x_{A} q_{0}^{A}(T)+x_{B} q_{I}^{B}(T)+\sum_{i=0}^{I}\left(\frac{i}{I} x_{i}^{A}\right)\left(q_{I}^{A}(T)-q_{0}^{A}(T)\right)+\sum_{i=0}^{I}\left[\left(\frac{I-i}{I}\right)^{2} x_{i}^{B}\right]\left(q_{0}^{B}(T)-q_{I}^{B}(T)\right)$ \\
\hline 3 & I III & $q(x, T)=x_{A} q_{0}^{A}(T)+x_{B} q_{I}^{B}(T)+\sum_{i=0}^{I}\left(\frac{i}{I} x_{i}^{A}\right)\left(q_{I}^{A}(T)-q_{0}^{A}(T)\right)+\sum_{i=0}^{I}\left[\frac{2 I(I-i)-(I-i)^{2}}{I^{2}} x_{i}^{B}\right]\left(q_{0}^{B}(T)-q_{I}^{B}(T)\right)$ \\
\hline 4 & II I & $q(x, T)=x_{A} q_{0}^{A}(T)+x_{B} q_{I}^{B}(T)+\sum_{i=0}^{I}\left[\left(\frac{i}{I}\right)^{2} x_{i}^{A}\right]\left(q_{I}^{A}(T)-q_{0}^{A}(T)\right)+\sum_{i=0}^{I}\left(\frac{I-i}{I} x_{i}^{B}\right)\left(q_{0}^{B}(T)-q_{I}^{B}(T)\right)$ \\
\hline 5 & II II & $q(x, T)=x_{A} q_{0}^{A}(T)+x_{B} q_{I}^{B}(T)+\sum_{i=0}^{I}\left[\left(\frac{i}{I}\right)^{2} x_{i}^{A}\right]\left(q_{I}^{A}(T)-q_{0}^{A}(T)\right)+\sum_{i=0}^{I}\left[\left(\frac{I-i}{I}\right)^{2} x_{i}^{B}\right]\left(q_{0}^{B}(T)-q_{I}^{B}(T)\right)$ \\
\hline 6 & II III & $q(x, T)=x_{A} q_{0}^{A}(T)+x_{B} q_{I}^{B}(T)+\sum_{i=0}^{I}\left[\left(\frac{i}{I}\right)^{2} x_{i}^{A}\right]\left(q_{I}^{A}(T)-q_{0}^{A}(T)\right)+\sum_{i=0}^{I}\left[\frac{2 I(I-i)-(I-i)^{2}}{I^{2}} x_{i}^{B}\right]\left(q_{0}^{B}(T)-q_{I}^{B}(T)\right)$ \\
\hline 7 & III I & $q(x, T)=x_{A} q_{0}^{A}(T)+x_{B} q_{I}^{B}(T)+\sum_{i=0}^{I}\left(\frac{2 I i-i^{2}}{I^{2}} x_{i}^{A}\right)\left(q_{I}^{A}(T)-q_{0}^{A}(T)\right)+\sum_{i=0}^{I}\left(\frac{I-i}{I} x_{i}^{B}\right)\left(q_{0}^{B}(T)-q_{I}^{B}(T)\right)$ \\
\hline 8 & III II & $q(x, T)=x_{A} q_{0}^{A}(T)+x_{B} q_{I}^{B}(T)+\sum_{i=0}^{I}\left(\frac{2 I i-i^{2}}{I^{2}} x_{i}^{A}\right)\left(q_{I}^{A}(T)-q_{0}^{A}(T)\right)+\sum_{i=0}^{I}\left[\left(\frac{I-i}{I}\right)^{2} x_{i}^{B}\right]\left(q_{0}^{B}(T)-q_{I}^{B}(T)\right)$ \\
\hline 9 & III III & $q(x, T)=x_{A} q_{0}^{A}(T)+x_{B} q_{I}^{B}(T)+\sum\left(\frac{2 I i-i^{2}}{I^{2}} x_{i}^{A}\right)\left(q_{I}^{A}(T)-q_{0}^{A}(T)\right)+\sum_{i=0}^{I}\left[\frac{2 I(I-i)-(I-i)^{2}}{I^{2}} x_{i}^{B}\right]\left(q_{0}^{B}(T)-q_{I}^{B}(T)\right)$ \\
\hline
\end{tabular}
or even a leaf of this tree. It means also that the whole information of a system can be obtained from the infor-

Table S1. Nine general $q(x, T)$-functions of alloy phases at $\mathbf{T} \mathbf{K}^{*}$.

*: Here, the $x_{i}^{A}=x_{i}^{A}(x, T)$ and $x_{i}^{B}=x_{i}^{B}(x, T)$. 
Table S2. $q(x, T)$-functions of disordered alloy phases at $\mathrm{T} \mathrm{K}$.

\begin{tabular}{|c|c|c|}
\hline No. & $\begin{array}{l}\text { Type } \\
\text { A B }\end{array}$ & Functions \\
\hline 1 & I I & $q(x, T)=x_{A} q_{0}^{A}(T)+x_{B} q_{I}^{B}(T)+x_{A} x_{B}\left(\left(q_{I}^{A}(T)-q_{0}^{A}(T)\right)+\left(q_{0}^{B}(T)-q_{I}^{B}(T)\right)\right)$ \\
\hline 2 & I II & $q(x, T)=x_{A} q_{0}^{A}(T)+x_{B} q_{I}^{B}(T)+x_{A} x_{B}\left(q_{I}^{A}(T)-q_{0}^{A}(T)\right)+\frac{(I-1) x_{A}^{2} x_{B}+x_{A} x_{B}}{I}\left(q_{0}^{B}(T)-q_{I}^{B}(T)\right)$ \\
\hline 3 & I III & $q(x, T)=x_{A} q_{0}^{A}(T)+x_{B} q_{I}^{B}(T)+x_{A} x_{B}\left(q_{I}^{A}(T)-q_{0}^{A}(T)\right)+\frac{(I-1) x_{A} x_{B}^{2}+I x_{A} x_{B}}{I}\left(q_{0}^{B}(T)-q_{I}^{B}(T)\right)$ \\
\hline 4 & II I & $q(x, T)=x_{A} q_{0}^{A}(T)+x_{B} q_{I}^{B}(T)+\frac{(I-1) x_{A} x_{B}^{2}+x_{A} x_{B}}{I}\left(q_{I}^{A}(T)-q_{0}^{A}(T)\right)+x_{A} x_{B}\left(q_{0}^{B}(T)-q_{I}^{B}(T)\right)$ \\
\hline 5 & II II & $q(x, T)=x_{A} q_{0}^{A}(T)+x_{B} q_{I}^{B}(T)+\frac{(I-1) x_{A} x_{B}^{2}+x_{A} x_{B}}{I}\left(q_{I}^{A}(T)-q_{0}^{A}(T)\right)+\frac{(I-1) x_{A}^{2} x_{B}+x_{A} x_{B}}{I}\left(q_{0}^{B}(T)-q_{I}^{B}(T)\right)$ \\
\hline 6 & II III & $q(x, T)=x_{A} q_{0}^{A}(T)+x_{B} q_{I}^{B}(T)+\frac{(I-1) x_{A} x_{B}^{2}+x_{A} x_{B}}{I}\left(q_{I}^{A}(T)-q_{0}^{A}(T)\right)+\frac{(I-1) x_{A}^{2} x_{B}+I x_{A} x_{B}}{I}\left(q_{0}^{B}(T)-q_{I}^{B}(T)\right)$ \\
\hline 7 & III I & $q(x, T)=x_{A} q_{0}^{A}(T)+x_{B} q_{I}^{B}(T)+\frac{(I-1) x_{A}^{2} x_{B}+I x_{A} x_{B}}{I}\left(q_{I}^{A}(T)-q_{0}^{A}(T)\right)+x_{A} x_{B}\left(q_{0}^{B}(T)-q_{I}^{B}(T)\right)$ \\
\hline 8 & III II & $q(x, T)=x_{A} q_{0}^{A}(T)+x_{B} q_{I}^{B}(T)+\frac{(I-1) x_{A}^{2} x_{B}+I x_{A} x_{B}}{I}\left(q_{I}^{A}(T)-q_{0}^{A}(T)\right)+\frac{(I-1) x_{A}^{2} x_{B}+x_{A} x_{B}}{I}\left(q_{0}^{B}(T)-q_{I}^{B}(T)\right)$ \\
\hline 9 & III III & $q(x, T)=x_{A} q_{0}^{A}(T)+x_{B} q_{I}^{B}(T)+\frac{(I-1) x_{A}^{2} x_{B}+I x_{A} x_{B}}{I}\left(q_{I}^{A}(T)-q_{0}^{A}(T)\right)+\frac{(I-1) x_{A} x_{B}^{2}+I x_{A} x_{B}}{I}\left(q_{0}^{B}(T)-q_{I}^{B}(T)\right)$ \\
\hline
\end{tabular}

mation of it's a few parts.

Due to the discovery of alloy genes and the establishments of holographic alloy positioning (HAP) system and a big database consisting of the AG-database and the holographic network phase diagrams of alloy systems, a standard method for researchers to share predictive algorithms and computational methods may be produced. The whole information of an alloy system and a designed alloy may be obtained. This study will create a new way of intelligent design advanced alloys and lead to fundamental variations in the metallic materials science.

\subsection{The Choices of Potential Energy E-function and Volume V-function in the Au-Cu System}

The $5^{\text {th }}$ E-function in Supplementary Table S1 has been chosen for describing $\mathrm{Au}-\mathrm{Cu}$ system, according to the calculated values of the mixed enthalpies

$\Delta H^{m}\left(x, 0, \sigma_{\max }\right)$, excess potential energies $\Delta E^{e x}\left(x, 0, \sigma_{\max }\right)$ and the lowest critical temperatures $T_{c}(x)$ of $\mathrm{AuCu}$ - and $\mathrm{AuCu}_{3}$-type sublattice ordered $\mathrm{Au}_{(1-x)} \mathrm{Cu}_{x}$ alloys with maximum order degrees, based on potential energies of the $A_{i}^{\mathrm{Au}}$ - and $A_{i}^{\mathrm{Cu}}$-sequences separated from mixed enthalpies of the $\mathrm{AuCu}$ and $\mathrm{AuCu}_{3}$ compounds respectively by nine E-functions at room temperature (Supplementary Figure S3).

The $6^{\text {th }}$ V-function in Supplementary Table S1 has been chosen for describing $\mathrm{Au}-\mathrm{Cu}$ system, according to the calculated values of the mixed volumes $\Delta v^{m}\left(x, T_{r}, \sigma_{\max }\right)$ and excess volumes $\Delta v^{e x}\left(x, T_{r}, \sigma_{\max }\right)$ of the $\mathrm{AuCu}-$ and $\mathrm{AuCu}_{3}$-type sublattice ordered $\mathrm{Au}_{(1-x)} \mathrm{Cu}_{x}$ alloys with maximum order degrees based on volumes of the $A_{i}^{\mathrm{Au}}$ and $A_{i}^{\mathrm{Cu}}$-sequences separated from experimental volumes of $\mathrm{AuCu}$ and $\mathrm{AuCu}_{3}$ compounds respectively by the $2^{\text {nd }}-9^{\text {th }} v$-functions at room temperature (Supplementary Figure S4).

In the $\mathrm{Au}-\mathrm{Cu}$ system, the correlative function between potential energies of alloy genes is,

$$
\left\{\begin{array}{l}
\varepsilon_{i}^{\mathrm{Au}}=\varepsilon_{0}^{\mathrm{Au}}+(i / I)^{2}\left(\varepsilon_{I}^{\mathrm{Au}}-\varepsilon_{0}^{\mathrm{Au}}\right) \\
\varepsilon_{i}^{\mathrm{Cu}}=\varepsilon_{I}^{\mathrm{Cu}}+[(I-i) / I]^{2}\left(\varepsilon_{0}^{\mathrm{Cu}}-\varepsilon_{I}^{\mathrm{Cu}}\right) .
\end{array}\right.
$$

The potential energy function of alloys is,

$$
\begin{aligned}
\varepsilon(x, T)= & x_{\mathrm{Au}} \varepsilon_{0}^{\mathrm{Au}}(T)+x_{\mathrm{Cu}} \varepsilon_{I}^{\mathrm{Cu}}(T) \\
& +\sum_{i=0}^{I}\left[\left(\frac{i}{I}\right)^{2} x_{i}^{\mathrm{Au}}\right]\left(\varepsilon_{I}^{\mathrm{Au}}(T)-\varepsilon_{0}^{\mathrm{Au}}(T)\right) \\
& +\sum_{i=0}^{I}\left[\left(\frac{I-i}{I}\right)^{2} x_{i}^{\mathrm{Cu}}\right]\left(\varepsilon_{0}^{\mathrm{Cu}}(T)-\varepsilon_{I}^{\mathrm{Cu}}(T)\right)
\end{aligned}
$$

The correlative function between volumes of alloy genes is:

$$
\left\{\begin{aligned}
v_{i}^{\mathrm{Au}}= & v_{0}^{\mathrm{Au}}+(i / I)^{2}\left(v_{I}^{\mathrm{Au}}-v_{0}^{\mathrm{Au}}\right) \\
v_{i}^{\mathrm{Cu}}= & v_{I}^{\mathrm{Cu}}+[2(I-i) / I]\left(v_{0}^{\mathrm{Cu}}-v_{I}^{\mathrm{Cu}}\right) \\
& -[(I-i) / I]^{2}\left(v_{0}^{\mathrm{Cu}}-v_{I}^{\mathrm{Cu}}\right)
\end{aligned}\right.
$$



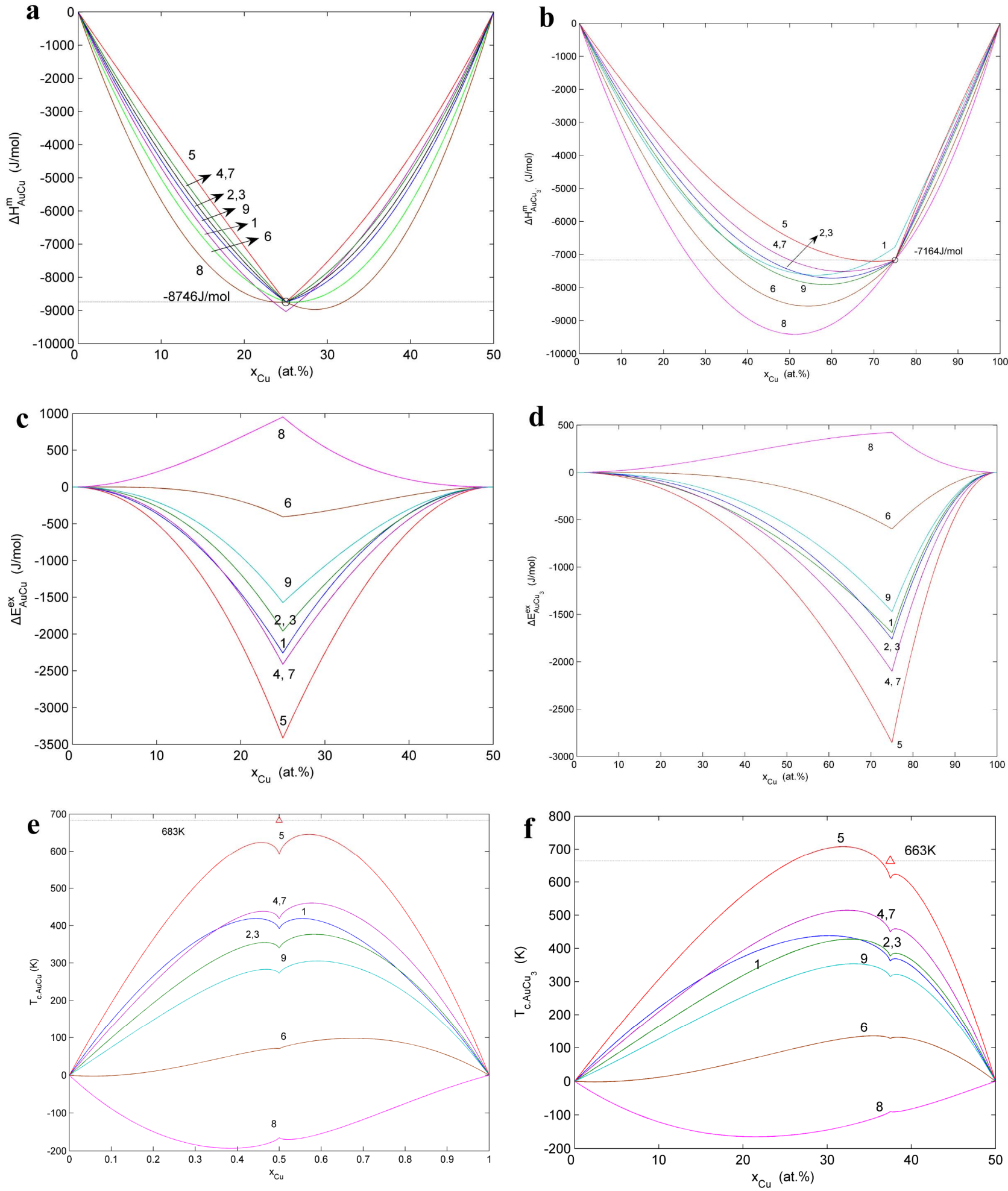

Figure S3. Energetic properties and critical temperatures of $\mathrm{AuCu}$ - and $\mathrm{AuCu}$-type sublattice ordered $\mathrm{Au}_{(1-x)} \mathrm{Cu}_{x}$ alloys with maximal order degrees calculated by nine E-functions. a), b) Mixed enthalpy $\Delta H_{\mathrm{AuCu}}^{m}(x)$ and $\Delta H_{\mathrm{AuCu}_{3}}^{m}(x)$, here the experimental values are denoted by symbol "O"; c), d) Excess potential energy differences $\Delta E_{\mathrm{AuCu}}^{e x}(x)$ and $\Delta E_{\mathrm{AuCu}}^{e x}(x)$ relative to disordered $\mathrm{Au}_{(1-x)} \mathrm{Cu}_{x}$ alloys; e), f) Critical temperature $T_{c, \mathrm{AuCu}}^{m}(x)$ and $\boldsymbol{T}_{c, \mathrm{AuCu}}^{m}(x)$, here the experimental values are denoted by symbol " $\triangle$ ". 

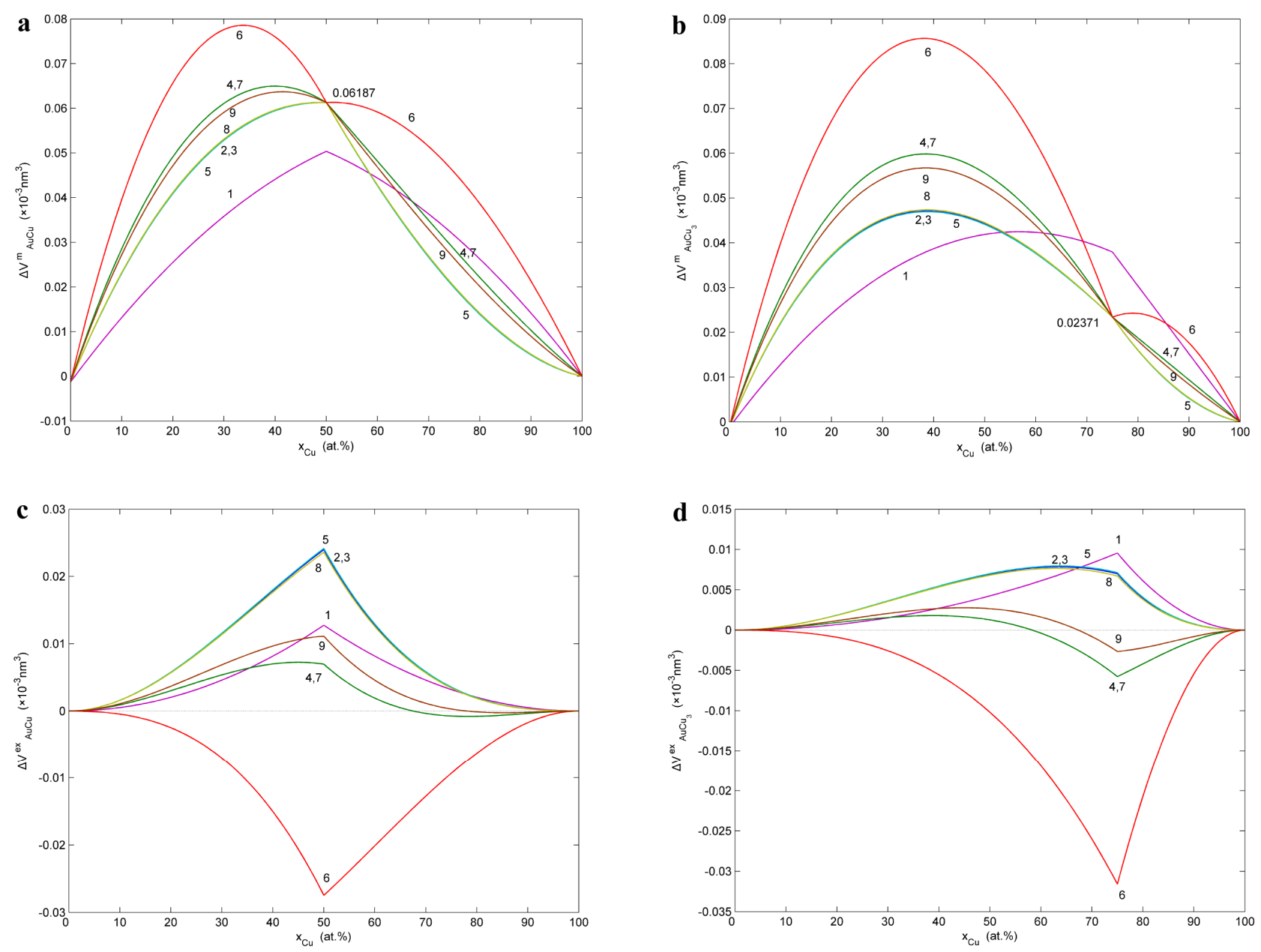

Figure S4. Volumetric properties of $\mathrm{AuCu}$ - and $\mathrm{AuCu}_{3}$-type sublattice ordered $\mathrm{Au}_{(1-x)} \mathrm{Cu}_{x}$ alloys with maximal order degrees calculated by nine $V$-functions. a), b) Mixed volumes of formation $\Delta V_{\mathrm{AuCu}}^{m}(x)$ and $\Delta V_{\mathrm{AuCu}_{3}}^{m}(x)$; c), d) Excess volume differences $\Delta V_{\mathrm{AuCu}}^{e x}(x)$ and $\Delta V_{\mathrm{AuCu}_{3}}^{e x}(x)$ relative to disordered $\mathrm{Au}_{(1-x)} \mathrm{Cu}_{x}$ alloys.

The volume function of alloys is,

$$
\begin{aligned}
& v(x, T)=x_{\mathrm{Au}} v_{0}^{\mathrm{Au}}(T)+x_{\mathrm{Cu}} v_{I}^{\mathrm{Cu}}(T) \\
& +\sum_{i=0}^{I}\left[\left(\frac{i}{I}\right)^{2} x_{i}^{\mathrm{Au}}\right]\left(v_{I}^{\mathrm{Au}}(T)-v_{0}^{\mathrm{Au}}(T)\right) \\
& +\sum_{i=0}^{I}\left[\frac{2 I(I-i)-(I-i)^{2}}{I^{2}} x_{i}^{B}\right] \cdot\left(v_{0}^{\mathrm{Cu}}(T)-v_{I}^{\mathrm{Cu}}(T)\right)
\end{aligned}
$$

where, $\varepsilon_{0}^{\mathrm{Au}}=-3.8140 \mathrm{eV}, \varepsilon_{I}^{\mathrm{Au}}=-4.0555 \mathrm{eV}$, $\varepsilon_{0}^{\mathrm{Cu}}=-3.6488 \mathrm{eV}, \quad \varepsilon_{I}^{\mathrm{Cu}}=-3.4824 \mathrm{eV}$;

$v_{0}^{\mathrm{Au}}=16.9581\left(10^{-3} \mathrm{~nm}^{3}\right), v_{I}^{\mathrm{Au}}=15.5213\left(10^{-3} \mathrm{~nm}^{3}\right)$,

$v_{0}^{\mathrm{Cu}}=12.6828\left(10^{-3} \mathrm{~nm}^{3}\right), \quad v_{I}^{\mathrm{Cu}}=11.8124\left(10^{-3} \mathrm{~nm}^{3}\right), I=$ 12.

Their features are as follows (Supplementary Figures 2(b) and (c), Supplementary Table S2):

The $\varepsilon_{i}^{\mathrm{Au}}$ decreases with increasing number $i$ of $\mathrm{Cu}-$ atoms in the coordinative configuration:

$\left(\varepsilon_{i}^{\mathrm{Au}}-\varepsilon_{0}^{\mathrm{Au}}\right)=(i / I)^{2}\left(\varepsilon_{I}^{\mathrm{Au}}-\varepsilon_{0}^{\mathrm{Au}}\right)$.
The $\varepsilon_{i}^{\mathrm{Cu}}$ decreases with increasing number (I-i) of Au-atoms in the coordinative configuration: $\left(\varepsilon_{i}^{\mathrm{Cu}}-\varepsilon_{I}^{\mathrm{Cu}}\right)=[(I-i) / I]^{2}\left(\varepsilon_{0}^{\mathrm{Cu}}-\varepsilon_{I}^{\mathrm{Cu}}\right)$.

The $v_{i}^{\mathrm{Au}}$ decreases with increasing number $i$ of $\mathrm{Cu}$ atoms in the coordinative configuration: $\left(v_{i}^{\mathrm{Au}}-v_{0}^{\mathrm{Au}}\right)=(i / I)^{2}\left(v_{I}^{\mathrm{Au}}-v_{0}^{\mathrm{Au}}\right)$.

The $v_{i}^{\mathrm{Cu}}$ increase with increasing number (I-i) of Auatoms in the coordinative configuration:

$$
\begin{aligned}
\left(v_{i}^{\mathrm{Cu}}-v_{I}^{\mathrm{Cu}}\right)= & {[2(I-i) / I]\left(v_{0}^{\mathrm{Cu}}-v_{I}^{\mathrm{Cu}}\right) } \\
& -[(I-i) / I]^{2}\left(v_{0}^{\mathrm{Cu}}-v_{I}^{\mathrm{Cu}}\right)
\end{aligned} .
$$

\subsection{Valence Electron Structures of AG-Sequences}

It is a very-very difficult problem to obtain electronic structures, physical and thermodynamic properties of alloy genes. After knowing the potential energies and volumes of alloy genes, a fictitious 'characteristic crys- 
tal' has been proposed in order to resolve this difficult problem. It is an fcc-based consisting of the same alloy genes with known potential energy and volume in the fcc-based lattice $\mathrm{Au}-\mathrm{Cu}$ system. Therefore, there are $C_{i}^{\mathrm{Au}}$ - and $C_{i}^{\mathrm{Cu}}$-sequences of characteristic crystals corresponding to $A_{i}^{\mathrm{Au}}$ - and $A_{i}^{\mathrm{Cu}}$-sequences. The $C_{0}^{\mathrm{Au}}$ and $C_{12}^{\mathrm{Cu}}$ are called as primary state characteristic crystals, i.e., $\mathrm{Au}-$ and $\mathrm{Cu}-$ pure metals. The $C_{12}^{\mathrm{Au}}$ and $C_{0}^{\mathrm{Cu}}$ are called as terminal state characteristic crystals.
After knowing the potential energies and volumes of alloy genes, the valence electron structures, single bond radii and potential energy curves of alloy genes can be calculated based on the valence bond theory of characteristic crystals and using inverse calculation method; and then, the Debye temperatures and bulk moduli of characteristic crystals can be obtained. These results are shown in Supplementary Figures S2(d) and (e), and listed in Supplementary Table S3. The valence electron

Table S3. The valence electron structures (the number of free electrons $\left(s_{f}\right)$, covalent electrons $\left(s_{c}, d_{c}\right)$ and non-valent electrons $\left.\left(d_{n}\right)\right)$, volumes( $(v)$, potential energies $(\varepsilon)$ and single bond radii $(R)$ of alloy genes, cohesive energy $\left(E_{c}\right)$, Debye temperatures $(\theta)$ and bulk moduli (B) of characteristic crystals.

\begin{tabular}{|c|c|c|c|c|c|c|c|c|c|c|}
\hline \multirow{2}{*}{$C_{i}^{\alpha}$} & \multicolumn{4}{|c|}{ valence electrons in outer shell } & \multirow{2}{*}{$\frac{v}{10^{-3} \mathrm{~nm}^{3}}$} & \multirow{2}{*}{$\begin{array}{c}\frac{\varepsilon}{(e V / a t .)} \\
\end{array}$} & \multirow{2}{*}{$\begin{array}{c}R \\
10^{-1} \mathrm{~nm}\end{array}$} & \multirow{2}{*}{$\frac{E_{c}}{(\mathrm{~J} / \mathrm{mol})}$} & \multirow{2}{*}{$\begin{array}{c}\theta \\
(\mathrm{K})\end{array}$} & \multirow{2}{*}{$\frac{B}{(\mathrm{GPa})}$} \\
\hline & $d_{n}$ & $d_{c}$ & $s_{c}$ & $s_{f}$ & & & & & & \\
\hline \multicolumn{11}{|c|}{$\underline{\text { Au characteristic crystals }}$} \\
\hline$C_{0}^{\mathrm{Au}}$ & 3.4013 & 5.8506 & 0 & 1.7481 & 16.9581 & -3.8130 & 1.3428 & 368000 & 165.00 & 170.99 \\
\hline$C_{1}^{\mathrm{Au}}$ & 3.4016 & 5.8523 & 0 & 1.7461 & 16.9524 & -3.8146 & 1.3426 & 368162 & 165.06 & 171.17 \\
\hline$C_{2}^{\mathrm{Au}}$ & 3.4007 & 5.8578 & 0 & 1.7415 & 16.9353 & -3.8197 & 1.3423 & 368647 & 165.22 & 171.69 \\
\hline$C_{3}^{\mathrm{Au}}$ & 3.3995 & 5.8669 & 0 & 1.7336 & 16.9067 & -3.8281 & 1.3417 & 369456 & 165.49 & 172.58 \\
\hline$C_{4}^{\mathrm{Au}}$ & 3.399 & 5.8793 & 0 & 1.7216 & 16.8667 & -3.8398 & 1.3409 & 370589 & 165.87 & 173.83 \\
\hline$C_{5}^{\mathrm{Au}}$ & 3.3994 & 5.8951 & 0 & 1.7055 & 16.8152 & -3.8549 & 1.3397 & 372046 & 166.37 & 175.45 \\
\hline$C_{6}^{\mathrm{Au}}$ & 3.3998 & 5.9143 & 0 & 1.6859 & 16.7524 & -3.8733 & 1.3383 & 373826 & 166.98 & 177.46 \\
\hline$C_{7}^{\mathrm{Au}}$ & 3.4005 & 5.9368 & 0 & 1.6627 & 16.6780 & -3.8951 & 1.3367 & 375929 & 167.70 & 179.86 \\
\hline$C_{8}^{\mathrm{Au}}$ & 3.4014 & 5.9626 & 0 & 1.636 & 16.5923 & -3.9203 & 1.3348 & 378357 & 168.52 & 182.68 \\
\hline$C_{9}^{\mathrm{Au}}$ & 3.404 & 5.9912 & 0 & 1.6048 & 16.4951 & -3.9488 & 1.3326 & 381108 & 169.47 & 185.94 \\
\hline$C_{10}^{\mathrm{Au}}$ & 3.4074 & 6.0229 & 0 & 1.5698 & 16.3865 & -3.9806 & 1.3302 & 384182 & 170.52 & 189.67 \\
\hline$C_{11}^{\mathrm{Au}}$ & 3.4138 & 6.0569 & 0 & 1.5293 & 16.2665 & -4.0159 & 1.3274 & 387581 & 171.70 & 193.89 \\
\hline$C_{12}^{\mathrm{Au}}$ & 3.4218 & 6.0936 & 0 & 1.4847 & 16.1351 & -4.0544 & 1.3244 & 391303 & 172.99 & 198.65 \\
\hline \multicolumn{11}{|c|}{$\underline{\mathrm{Cu} \text { characteristic crystals }}$} \\
\hline$C_{0}^{\mathrm{Cu}}$ & 4.2877 & 5.0495 & 0 & 1.6628 & 12.3631 & -3.6478 & 1.1793 & 352055 & 345.81 & 134.68 \\
\hline$C_{1}^{\mathrm{Cu}}$ & 4.3485 & 5.0119 & 0 & 1.6396 & 12.3593 & -3.6212 & 1.1782 & 349491 & 344.58 & 133.76 \\
\hline$C_{2}^{\mathrm{Cu}}$ & 4.411 & 4.9762 & 0 & 1.6129 & 12.3478 & -3.5969 & 1.1768 & 347150 & 343.53 & 133.05 \\
\hline$C_{3}^{\mathrm{Cu}}$ & 4.4737 & 4.9426 & 0 & 1.5837 & 12.3287 & -3.5750 & 1.1753 & 345031 & 342.66 & 132.56 \\
\hline$C_{4}^{\mathrm{Cu}}$ & 4.5366 & 4.9111 & 0 & 1.5523 & 12.3019 & -3.5553 & 1.1735 & 343136 & 341.96 & 132.27 \\
\hline$C_{5}^{\mathrm{Cu}}$ & 4.6006 & 4.8815 & 0 & 1.5179 & 12.2675 & -3.5380 & 1.1715 & 341463 & 341.45 & 132.20 \\
\hline$C_{6}^{\mathrm{Cu}}$ & 4.6648 & 4.854 & 0 & 1.4812 & 12.2254 & -3.5230 & 1.1693 & 340014 & 341.10 & 132.34 \\
\hline$C_{7}^{\mathrm{Cu}}$ & 4.7309 & 4.8282 & 0 & 1.4409 & 12.1757 & -3.5103 & 1.1669 & 338787 & 340.96 & 132.70 \\
\hline$C_{8}^{\mathrm{Cu}}$ & 4.7982 & 4.8042 & 0 & 1.3976 & 12.1183 & -3.4999 & 1.1642 & 337784 & 340.99 & 133.28 \\
\hline$C_{9}^{\mathrm{Cu}}$ & 4.866 & 4.7821 & 0 & 1.3519 & 12.0533 & -3.4918 & 1.1612 & 337003 & 341.21 & 134.09 \\
\hline$C_{10}^{\mathrm{Cu}}$ & 4.9345 & 4.7618 & 0 & 1.3037 & 11.9807 & -3.4860 & 1.1581 & 336446 & 341.61 & 135.15 \\
\hline$C_{11}^{\mathrm{Cu}}$ & 5.0053 & 4.7429 & 0 & 1.2519 & 11.9003 & -3.4826 & 1.1547 & 336111 & 342.20 & 136.44 \\
\hline$C_{12}^{\mathrm{Cu}}$ & 5.0778 & 4.7254 & 0 & 1.1968 & 11.8124 & -3.4814 & 1.1511 & 336000 & 343.00 & 138.00 \\
\hline
\end{tabular}


structures of characteristic crystals may represent ones of alloy genes and their physical properties may represent the contributions of alloy genes to properties of alloys.

In the free atom system, the electron structures of atoms are described by four quantum numbers. The outshell electron structures of the $\mathrm{Au}-$ and $\mathrm{Cu}$ - free atoms at the basic states are respectively $5 d^{10} 6 s^{1}$ and $3 d^{10} 4 s^{1}$.

The electronic structure units of the alloy genes are valence electrons described by four quantum numbers: free electron $\left(s_{f}\right)$, covalent electron $\left(s_{c}, p_{c}, d_{c}, f_{c}\right)$, magnetic electron $\left(d_{m}, f_{m}\right)$ and non-valence electron $\left(p_{n}, d_{n}, f_{n}\right)$. In the $\mathrm{Au}-\mathrm{Cu}$ system, the valence electron structures of AG-sequences are listed in Supplementary Table S3. The valence electron structures of the primary states $\left(\psi_{0}^{\mathrm{Au}}, \psi_{12}^{\mathrm{Cu}}\right)$ and terminal states $\left(\psi_{12}^{\mathrm{Au}}, \psi_{0}^{\mathrm{Cu}}\right)$ of alloy genes are as follows:

$$
\begin{aligned}
& \psi_{0}^{\mathrm{Au}}=5 d_{n}^{3.4013} 5 d_{c}^{5.8506} 6 s_{f}^{1.7481} \\
& \psi_{12}^{\mathrm{Au}}=5 d_{n}^{3.4218} 5 d_{c}^{6.0936} 6 s_{f}^{1.4847} . \\
& \psi_{12}^{\mathrm{Cu}}=3 d_{n}^{5.0778} 3 d_{c}^{4.7254} 4 s_{f}^{1.1968} ; \\
& \psi_{0}^{\mathrm{Cu}}=3 d_{n}^{4.2877} 3 d_{c}^{5.04954} 4 s_{f}^{1.6628} .
\end{aligned}
$$

The essence of properties of alloy genes can be explained by their valence electron structures.

The essence for forming fcc-based lattice: As changing from $\psi_{0}^{\mathrm{Au}}$ to $\psi_{12}^{\mathrm{Au}}$, the $d_{n}$-electrons slightly increase (3.4012/atom $\rightarrow$ 3.4218/atom ) and occupy at the $d$-energy band $e_{g}$ state; and the $d_{c}$-electrons obviously increase (5.8506/atom $\rightarrow$ 6.0936/atom) and occupy at the $d$-energy band $t_{2 g}$ state. Therefore, each $A_{i}^{\mathrm{Au}}$-atom possesses 12 covalent bonds to form fcc-based lattice.

As changing from $\psi_{12}^{\mathrm{Cu}}$ to $\psi_{0}^{\mathrm{Cu}}$, the $d_{n}$-electrons obviously decrease (5.0778/atom $\rightarrow$ 4.2877/atom), few of them occupy at the d-energy band $t_{2 g}$ state, besides filling the $e_{g}$ state fully; the $d_{c}$-electrons obviously increase (4.7254/atom $\rightarrow 5.0495 /$ atom ) and occupy at the $d$-energy band $t_{2 g}$ state. Each $A_{i}^{\mathrm{Cu}}$-atom possesses 12 covalent bonds to form fcc-based lattice.

For these reasons, the intermetallics, ordered and disordered alloys formed by $A_{i}^{\mathrm{Au}}$ - and $A_{i}^{\mathrm{Cu}}$-sequences possess fcc-based lattice.

The essence for variations in potential energies and volumes of alloy genes:

As changing from $\psi_{0}^{\mathrm{Au}}$ to $\psi_{12}^{\mathrm{Au}}$, the $s_{f}$-electrons decrease: 1.7481 /atom $\rightarrow 1.4847 /$ atom, and the decreased $s_{f}$-electrons are translated into $d_{c}$-electrons. It results in falling $\varepsilon_{12}^{\mathrm{Au}}$ potential energy: $-3.813 \mathrm{eV} /$ atom $\rightarrow-4.0544 \mathrm{eV} /$ atom, shorting single bond radus: 1.3428 $\times 10^{-1} \mathrm{~nm} \rightarrow 1.3244 \times 10^{-1} \mathrm{~nm}$, and reducing $v_{12}^{\mathrm{Au}}$ volume: $16.9581 \times 10^{-3} \mathrm{~nm}^{3} \rightarrow 16.1351 \times 10^{-3} \mathrm{~nm}^{3}$. Therefore, The $\varepsilon_{i}^{\mathrm{Au}}$-potential energies decrease and the $v_{i}^{\mathrm{Au}}$-volumes reduce with increasing number $i$ of $\mathrm{Cu}$ - atoms in the coordinative configurations.

As changing from $\psi_{12}^{\mathrm{Cu}}$ to $\psi_{0}^{\mathrm{Cu}}$, the $s_{f}$-electrons increase: 1.1968 /atom $\rightarrow 1.6628 /$ atom, and the $d_{c^{-}}$electrons increase: 4.7254 /atom $\rightarrow 5.0495 /$ atom. It results in falling $\varepsilon_{0}^{\mathrm{Cu}}$ potential energy: $-3.4814 \mathrm{eV} /$ atom $\rightarrow$ $-3.6478 \mathrm{eV} /$ atom, lengthening single bond radius: 1.1511 $\times 10^{-1} \mathrm{~nm} \rightarrow 1.1793 \times 10^{-1} \mathrm{~nm}$, and expanding $v_{0}^{\mathrm{Cu}}$ volume: $11.8124 \times 10^{-3} \mathrm{~nm}^{3} \rightarrow 12.3631 \times 10^{-3} \mathrm{~nm}^{3}$. Therefore, the $\varepsilon_{i}^{\mathrm{Cu}}$-potential energies decrease and $v_{i}^{\mathrm{Cu}}$-volumes increases with increasing number $(I-i)$ of $\mathrm{Au}$-atoms in the coordinative configurations, that is contrary to the expected behavior.

\subsection{The Thermodynamics Properties of AG-Sequences}

In the SMMS framework, the Gibbs energy $\left(G_{i}(T)\right)$ of each characteristic crystal (or ally gene) may be split into two parts: a temperature-independent contribution of potential energy $(E(0))$, of which the variation with temperatures has been accounted in the attaching vibration energy, and a temperature-dependent contribution of generalized vibration free energy $\left(X^{v}(T)\right)$, but both are configuration $(i)$-dependent (Equation (9)). The enthalpy $\left(H_{i}(T)\right)$ of each characteristic crystal may be also split into two parts: a temperature-independent contribution of potential energy $(E(0))$ and a temperature-dependent contribution of generalized vibration energy $\left(U^{v}(T)\right)$ (Equation (10)). The generalized vibration free energy includes the generalized vibration energies $\left(U^{v}(T)\right)$, which include Debye vibration energies $\left(U^{D}(T)\right)$ and attaching vibration energies $\left(U^{E}(T)\right)$, and the contribution of the generalized vibration entropies $\left(S^{v}(T)\right)$, which include Debye vibration entropies $\left(S^{D}(T)\right)$ and attaching vibration entropies $\left(S^{E}(T)\right)$, the generalized vibration heat capacity $\left(C_{p}^{v}(T)\right)$, which include Debye vibration heat capacity $\left(C_{p}^{D}(T)\right)$, attaching vibration heat capacity $\left(C_{p}^{E}(T)\right)$. The attaching vibration energy includes contributions of electron excitation, energy of formation of holes, variation of potential energy with temperature, and so on. Therefore, the multi-level energetic functions of characteristic crystals at $T \mathrm{~K}$ as follows:

$$
\begin{gathered}
\left\{\begin{array}{l}
G_{i}^{\mathrm{Au}}(T)=E_{i}^{\mathrm{Au}}(0)+X_{i}^{\mathrm{Au} . v}(T)=H_{i}^{\mathrm{Au}}(T)-T S_{i}^{\mathrm{Au} . v}(T) \\
G_{i}^{\mathrm{Cu}}(T)=E_{i}^{\mathrm{Cu}}(0)+X_{i}^{\mathrm{Cu} . v}(T)=H_{i}^{\mathrm{Cu}}(T)-T S_{i}^{\mathrm{Cu} . v}(T)
\end{array}\right. \\
\left\{\begin{array}{l}
H_{i}^{\mathrm{Au}}(T)=E_{i}^{\mathrm{Au}}(0)+U_{i}^{\mathrm{Au} . v}(T) \\
H_{i}^{\mathrm{Cu}}(T)=E_{i}^{\mathrm{Cu}}(0)+U_{i}^{\mathrm{Cu} . v}(T)
\end{array}\right. \\
\left\{\begin{array}{l}
X_{i}^{\mathrm{Au} . v}(T)=U_{i}^{\mathrm{Au} . v}(T)-T S_{i}^{\mathrm{Au} . v}(T) \\
X_{i}^{\mathrm{Cu} . v}(T)=U_{i}^{\mathrm{Cu} . v}(T)-T S_{i}^{\mathrm{Cu} \cdot v}(T)
\end{array}\right.
\end{gathered}
$$




$$
\begin{gathered}
\left\{\begin{array}{l}
X_{i}^{\mathrm{Au} . D}(T)=U_{i}^{\mathrm{Au} . D}(T)-T S_{i}^{\mathrm{Au} . D}(T) \\
X_{i}^{\mathrm{Cu} . D}(T)=U_{i}^{\mathrm{Cu} . D}(T)-T S_{i}^{\mathrm{Cu} . D}(T)
\end{array}\right. \\
\left\{\begin{array}{l}
X_{i}^{\mathrm{Au} . E}(T)=U_{i}^{\mathrm{Au} . E}(T)-T S_{i}^{\mathrm{Au} . E}(T) \\
X_{i}^{\mathrm{Cu} . E}(T)=U_{i}^{\mathrm{Cu} . E}(T)-T S_{i}^{\mathrm{Cu} . E}(T)
\end{array}\right. \\
\left\{\begin{array}{l}
U_{i}^{\mathrm{Au} . v}(T)=U_{i}^{\mathrm{Au} . D}(T)+U_{i}^{\mathrm{Au} . E}(T) \\
U_{i}^{\mathrm{Cu} . v}(T)=U_{i}^{\mathrm{Cu} . D}(T)+U_{i}^{\mathrm{Cu} . E}(T)
\end{array}\right. \\
\left\{\begin{array}{l}
U_{i}^{\mathrm{Au} . D}(T)=\int_{0}^{T} C_{p . i}^{\mathrm{Au} . D}(T) \mathrm{d} T \\
U_{i}^{\mathrm{Cu} . D}(T)=\int_{0}^{T} C_{p . i}^{\mathrm{Cu} . D}(T) \mathrm{d} T
\end{array}\right.
\end{gathered}
$$$$
\left\{\begin{array}{l}
U_{i}^{\mathrm{Au} . E}(T)=\int_{0}^{T} C_{p . i}^{\mathrm{Au} . E}(T) \mathrm{d} T \\
U_{i}^{\mathrm{Cu} . E}(T)=\int_{0}^{T} C_{p . i}^{\mathrm{Cu} . E}(T) \mathrm{d} T
\end{array}\right.
$$$$
\left\{\begin{array}{l}
S_{i}^{\text {Au. } v}(T)=S_{i}^{\text {Au. } . D}(T)+S_{i}^{\text {Au. } E}(T) \\
S_{i}^{\text {Cu. } v}(T)=S_{i}^{\text {Cu. } . D}(T)+S_{i}^{\text {Cu. } E}(T)
\end{array}\right.
$$$$
\left\{\begin{array}{l}
S_{i}^{\mathrm{Au} . D}(T)=\int_{0}^{T} \frac{C_{p . i}^{\mathrm{Au} . D}(T)}{T} \mathrm{~d} T \\
S_{i}^{\mathrm{Cu} . D}(T)=\int_{0}^{T} \frac{C_{p . i}^{\mathrm{Cu} . D}(T)}{T} \mathrm{~d} T
\end{array}\right.
$$

$$
\begin{gathered}
\left\{\begin{array}{l}
C_{p .0}^{\text {Au. } E}(T)=1.858993 \times 10^{-10} T+4.222584 \times 10^{-6} T^{2} \\
C_{p .12}^{\text {Au. }}(T)=2.763134 \times 10^{-4} T+5.481502 \times 10^{-6} T^{2}
\end{array}\right. \\
\left\{\begin{array}{l}
C_{p .12}^{\text {Cu. } E}(T)=0.00168035 T+2.826912 \times 10^{-6} T^{2} \\
C_{p .0}^{\text {Cu. } E}(T)=0.00564614 T+3.632353 \times 10^{-6} T^{2}
\end{array}\right.
\end{gathered}
$$

where, $\theta_{0}^{\mathrm{Au}}=165 \mathrm{~K}, \theta_{12}^{\mathrm{Au}}=175.21 \mathrm{~K}, \theta_{12}^{\mathrm{Cu}}=343 \mathrm{~K}$, $\theta_{0}^{\mathrm{Cu}}=343.07 \mathrm{~K}$.

It can be demonstrated that the general correlative functions between other energetic properties $(q)$ of characteristic crystals (ally genes) at $T \mathrm{~K}$ are as follows

$$
\left\{\begin{array}{l}
q_{i}^{\mathrm{Au}}(T)=q_{0}^{\mathrm{Au}}(T)+(i / I)^{2}\left[q_{I}^{\mathrm{Au}}(T)-q_{0}^{\mathrm{Au}}(T)\right] \\
q_{i}^{\mathrm{Cu}}(T)=q_{I}^{\mathrm{Cu}}(T)+[(I-i) / I]^{2}\left[q_{0}^{\mathrm{Cu}}(T)-q_{\mathrm{I}}^{\mathrm{Cu}}(T)\right]
\end{array}\right.
$$

The AG-thermodynamic properties of characteristic crystals (ally genes) of Au-Cu system are shown in Supplementary Figure S5.

\section{Alloy Gene Gibbs Energy Partition Function}

In this section we present the AG-Gibbs energy partition function of AuCu-type sublattice alloy system, which includes AG-Gibbs energy transmission law, and AGarranging function, as well as other functions of thermodynamic properties.

Characteristic Gibbs energy function:

The characteristic Gibbs energy $G^{*}(x, T)$ function can be obtained by the AGT law (S1):

$$
G^{*}(x, T)=\sum_{i=0}^{12}\left(x_{i}^{\mathrm{Au}}(x, T) \times G_{i}^{\mathrm{Au}}(T)+x_{i}^{\mathrm{Cu}}(x, T) \times G_{i}^{\mathrm{Cu}}(T)\right)
$$

Partition function of the alloy:

$$
\begin{aligned}
\Omega(x, T)= & g\left(x_{i}^{\mathrm{Au}}(x, T), x_{i}^{\mathrm{Cu}}(x, T)\right) \\
& \times \exp \left[-G^{*}(x, T) /(k T)\right]
\end{aligned}
$$


Y. Q. XIE $E T A L$.

433
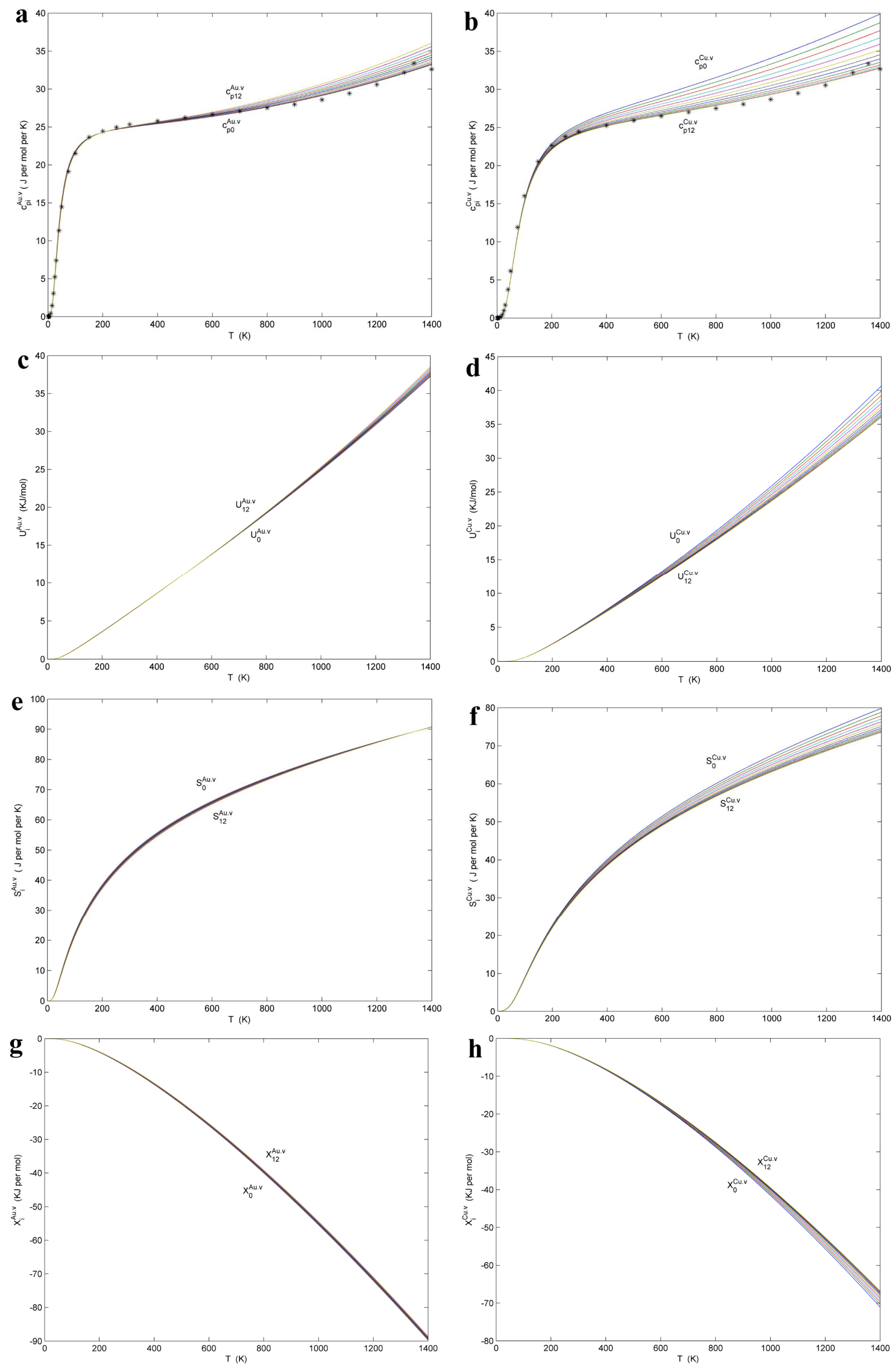

Copyright (C) 2013 SciRes.

IJCNS 

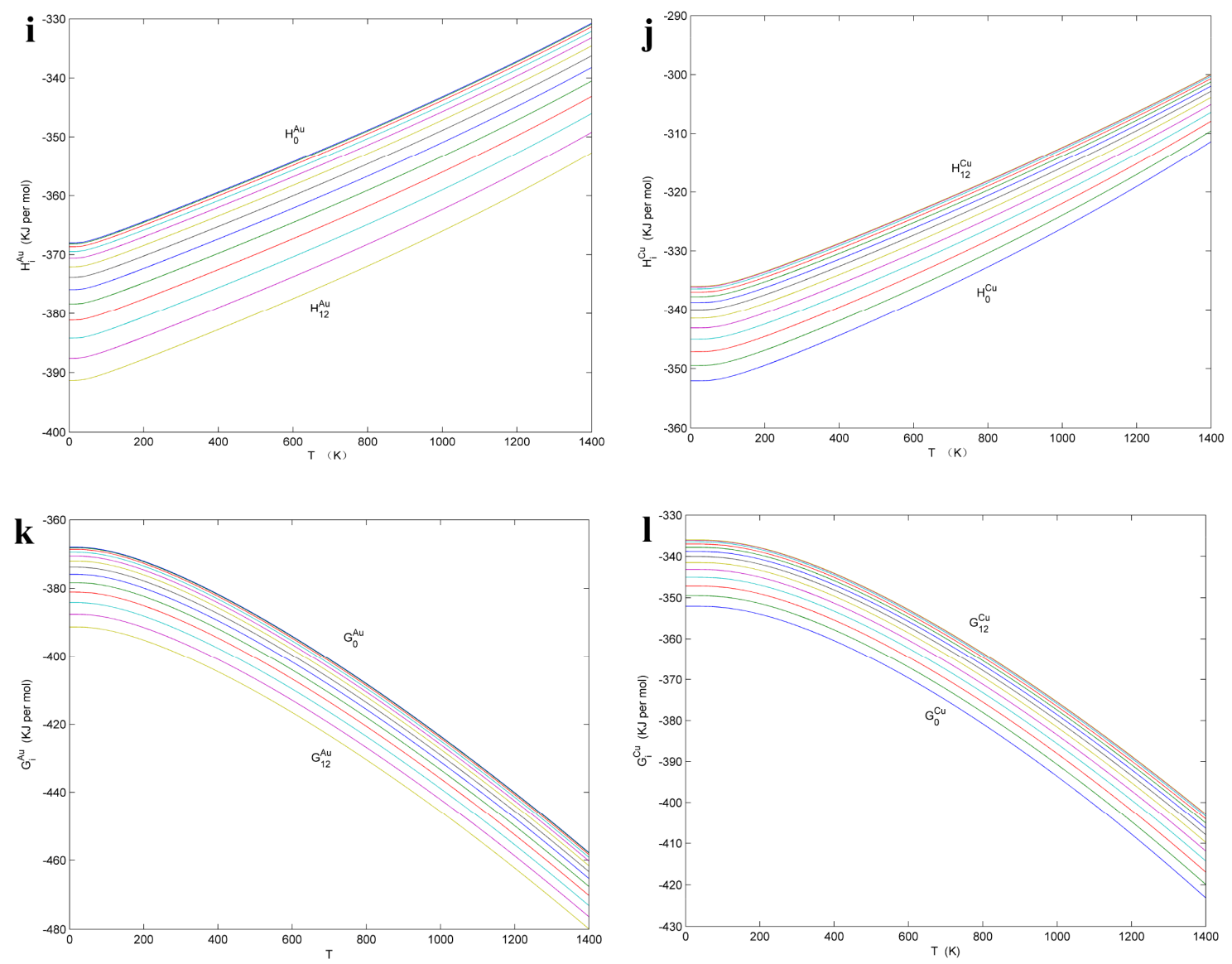

Figure S5. Curves of AG-thermodynamic properties in Au-Cu system. a), b) Generalized vibration heat capacity curves: $\left.C_{p .0}^{\text {Au.v }} \cdots C_{p i}^{v . A u} \cdots C_{p 12}^{v . \mathrm{Au}}, C_{p .0}^{\mathrm{Cu} . v} \cdots C_{p . i}^{\text {Cu.v }} \cdots C_{p .12}^{\text {Cu.v }} ; \mathrm{c}\right)$, d) Generalized vibration energy curves: $U_{0}^{\text {Au.v }} \cdots U_{i}^{\text {Au.v }} \cdots U_{12}^{\text {Au.v }}$,

$\left.U_{0}^{\text {Cu.v }} \cdots U_{i}^{\text {Cu.v }} \cdots U_{12}^{\text {Cu.v }} ; \mathrm{e}\right)$, f) Generalized vibration entropies curves: $S_{0}^{\text {Au.v }} \cdots S_{i}^{\text {Au.v }} \cdots S_{12}^{\text {Au.v }}, S_{0}^{\text {Cu.v }} \cdots S_{i}^{\text {Cu.v }} \cdots S_{12}^{\text {Cu.v }} ;$ g), h) Generalized vibration free energy curves: $X_{0}^{\text {Au.v }} \cdots X_{i}^{\text {Au.v }} \cdots X_{12}^{\text {Au.v }}, X_{0}^{\text {Cu.v }} \cdots X_{i}^{\text {Cu.v }} \cdots X_{12}^{\text {Cu.v }} ;$ i), j) Enthalpy of formation curves: $\left.H_{0}^{\mathrm{Au}} \cdots H_{i}^{\mathrm{Au}} \cdots H_{12}^{\mathrm{Au}}, \quad H_{0}^{\mathrm{Cu}} \cdots H_{i}^{\mathrm{Cu}} \cdots H_{12}^{\mathrm{Cu}} ; \mathrm{k}\right)$, l) Gibbs energy curves: $G_{0}^{\mathrm{Au}} \cdots G_{i}^{\mathrm{Au}} \cdots G_{12}^{\mathrm{Au}}, G_{12}^{\mathrm{Cu}} \cdots G_{i}^{\mathrm{Cu}} \cdots G_{0}^{\mathrm{Cu}} \cdot$

AG-arranging function extending to all $G_{i}^{\mathrm{Au}}$ - and $G_{i}^{\mathrm{Cu}}$-energy levels:

$g\left(x_{i}^{\mathrm{Au}}(x, T), x_{i}^{\mathrm{Cu}}(x, T)\right)$

$=\frac{\left[N \sum_{i=0}^{I}\left(x_{i}^{\mathrm{Au}(1)}+x_{i}^{\mathrm{Cu}(1)}\right)\right] !}{\left(\sum_{i=0}^{I} N x_{i}^{\mathrm{Au}(1)}\right) !\left(\sum_{i=0}^{I} N x_{i}^{\mathrm{Cu}(1)}\right) !} \times \frac{\left[N \sum_{i=0}^{I}\left(x_{i}^{\mathrm{Au}(2)}+x_{i}^{\mathrm{Cu}(2)}\right)\right] !}{\left(\sum_{i=0}^{I} N x_{i}^{\mathrm{Au}(2)}\right) !\left(\sum_{i=0}^{I} N x_{i}^{\mathrm{Cu}(2)}\right) !}$

Concentrations of the $A_{i}^{\mathrm{Au}}$ and $A_{i}^{\mathrm{Cu}}$ alloy genes at the $G_{i}^{\mathrm{Au}}(T)$ - and $G_{i}^{\mathrm{Cu}}(T)$-energy levels::

$$
\left\{\begin{array}{l}
x_{i}^{\mathrm{Au}}(x, T)=x_{i}^{\mathrm{Au}(1)}(x, T)+x_{i}^{\mathrm{Au}(2)}(x, T) \\
x_{i}^{\mathrm{Au}}(x, T)=x_{i}^{\mathrm{Au}(1)}(x, T)+x_{i}^{\mathrm{Au}(2)}(x, T)
\end{array}\right.
$$

Concentrations of the $A_{i}^{\mathrm{Au}}$ and $A_{i}^{\mathrm{Cu}}$ alloy genes occupied at the (1) and (2) sublattice points:

$$
\left\{\begin{array}{l}
x_{i}^{\mathrm{Au}(1)}(x, T)=v^{(1)} P_{\mathrm{Au}}^{(1)} \omega_{i}^{(1)} \\
x_{i}^{\mathrm{Cu}(1)}(x, T)=v^{(1)} P_{\mathrm{Cu}}^{(1)} \omega_{i}^{(1)} \\
x_{i}^{\mathrm{Au}(2)}(x, T)=v^{(2)} P_{\mathrm{Au}}^{(2)} \omega_{i}^{(2)} \\
x_{i}^{\mathrm{Cu}(2)}(x, T)=v^{(2)} P_{\mathrm{Cu}}^{(2)} \omega_{i}^{(2)}
\end{array}\right.
$$

Probabilities of $\mathrm{Au}$ and $\mathrm{Cu}$ atoms occupied at (1) and (2) sublattice points:

$$
\left\{\begin{array}{l}
P_{\mathrm{Au}}^{(1)}=x_{\mathrm{Au}}+\left(1-v^{(1)}\right) \sigma, \\
P_{\mathrm{Cu}}^{(1)}=1-P_{\mathrm{Au}}^{(1)}=1-\left[x_{\mathrm{Au}}+\left(1-v^{(1)}\right) \sigma\right] \\
P_{\mathrm{Au}}^{(2)}=x_{\mathrm{Au}}-v^{(1)} \sigma, \\
P_{\mathrm{Cu}}^{(2)}=1-P_{\mathrm{Au}}^{(2)}=1-\left(x_{\mathrm{Au}}-v^{(1)} \sigma\right) .
\end{array}\right.
$$

Fractions of the (1) and (2) sublattice points: 


$$
\begin{gathered}
\left\{\begin{array}{l}
v^{(1)}=N^{(1)} / N=1 / 2 \\
v^{(2)}=N^{(2)} / N=1 / 2
\end{array}\right. \\
\sigma=\frac{P_{\mathrm{Au}}^{(1)}-x_{\mathrm{Au}}}{1-v^{(1)}}=\frac{P_{\mathrm{Cu}}^{(2)}-x_{\mathrm{Cu}}}{1-v^{(2)}}=\frac{x_{i}^{\mathrm{Au}(1)}}{v^{(1)} v^{(2)} w_{i}^{(1)}}-\frac{x_{\mathrm{Au}}}{v^{(2)}}=\frac{x_{i}^{\mathrm{Cu}(2)}}{v^{(1)} v^{(2)} w_{i}^{(2)}}-\frac{x_{\mathrm{Cu}}}{v^{(1)}}
\end{gathered}
$$

The probability $\omega_{i}^{(1)}$ of the coordinative cluster $\quad[(I-i) \mathrm{Au}, i \mathrm{Cu}]$ surrounding the (1)-sublattice point:

$$
\omega_{i}^{(1)}=\omega_{i^{\prime}}^{(2)} \times \omega_{\left(i-i^{\prime}\right)}^{(1)}=\sum_{i=k^{\prime}}^{K}\left[C_{8}^{i^{\prime}}\left(P_{\mathrm{Au}}^{(2)}\right)^{\left(8-i^{\prime}\right)}\left(P_{\mathrm{Cu}}^{(2)}\right)^{\left(i^{\prime}\right)} \times C_{4}^{\left(i-i^{\prime}\right)}\left(P_{\mathrm{Au}}^{(1)}\right)^{\left[4-\left(i-i^{\prime}\right)\right]}\left(P_{\mathrm{Cu}}^{(1)}\right)^{\left(i-i^{\prime}\right)}\right]
$$

In the $\omega_{i}^{(1)}$ equation, the probability $\omega_{i^{\prime}}^{(2)}$ of coordinative cluster $\left[\left(8-i^{\prime}\right) \mathrm{Au}, i^{\prime} \mathrm{Cu}\right]$ occupied at the (2)-sublattice points, and the probability $\omega_{\left(i-i^{\prime}\right)}^{(2)}$ of co-

ordinative cluster $\left[4-\left(i-i^{\prime}\right) \mathrm{Au},\left(i-i^{\prime}\right) \mathrm{Cu}\right]$ occupied at the (1)-sublattice points:

$$
\left\{\begin{array}{l}
\omega_{i^{\prime}}^{(2)}=\sum_{i^{\prime}=k}^{K}\left[C_{8}^{i^{\prime}}\left(P_{\mathrm{Au}}^{(2)}\right)^{\left(8-i^{\prime}\right)}\left(P_{\mathrm{Cu}}^{(2)}\right)^{\left(i^{\prime}\right)}\right] \\
\omega_{\left(i-i^{\prime}\right)}^{(1)}=\sum_{i^{\prime}=k}^{K}\left[C_{4}^{\left(i-i^{\prime}\right)}\left(P_{\mathrm{Au}}^{(1)}\right)^{\left[4-\left(i-i^{\prime}\right)\right]}\left(P_{\mathrm{Cu}}^{(1)}\right)^{\left(i-i^{\prime}\right)}\right]
\end{array}\right.
$$

where, the $i^{\prime}$ is the number of the $\mathrm{Cu}$ atoms occupied at the (2)-sublattice points.
The probability $\omega_{i}^{(2)}$ of coordinative cluster $[(I-i) \mathrm{Au}, i \mathrm{Cu}]$ surrounding the (2)-sublattice point:

$$
\omega_{i}^{(2)}=\omega_{i^{\prime}}^{(1)} \times \omega_{\left(i-i^{\prime}\right)}^{(2)}=\sum_{i^{\prime}=k}^{K}\left[C_{8}^{i^{\prime}}\left(P_{\mathrm{Au}}^{(1)}\right)^{\left(8-i^{\prime}\right)}\left(P_{\mathrm{Cu}}^{(1)}\right)^{\left(i^{\prime}\right)} \times C_{4}^{\left(i-i^{\prime}\right)}\left(P_{\mathrm{Au}}^{(2)}\right)^{\left[4-\left(i-i^{\prime}\right)\right]}\left(P_{\mathrm{Cu}}^{(2)}\right)^{\left(i-i^{\prime}\right)}\right]
$$

where, the $i^{\prime}$ is the number of the $\mathrm{Cu}$ atoms occupied at the (1)-sublattice points.

In the $\omega_{i}^{(2)}$ equation, the probability $\omega_{i^{\prime}}^{(1)}$ of coordinative cluster $\left[\left(8-i^{\prime}\right) \mathrm{Au}, i^{\prime} \mathrm{Cu}\right]$ occupied at the (1)sublattice points, and the probability $\omega_{\left(i-i^{\prime}\right)}^{(2)}$ of coordinative cluster $\left[4-\left(i-i^{\prime}\right) \mathrm{Au},\left(i-i^{\prime}\right) \mathrm{Cu}\right]$ occupied at the (2)-sublattice points:

$$
\left\{\begin{array}{l}
\omega_{i^{\prime}}^{(1)}=\sum_{i^{\prime}=k}^{K}\left[C_{8}^{i^{\prime}}\left(P_{\mathrm{Au}}^{(1)}\right)^{\left(8-i^{\prime}\right)}\left(P_{\mathrm{Cu}}^{(1)}\right)^{\left(i^{\prime}\right)}\right] \\
\omega_{\left(i-i^{\prime}\right)}^{(2)}=\sum_{i^{\prime}=k}^{K}\left[C_{4}^{\left(i-i^{\prime}\right)}\left(P_{\mathrm{Au}}^{(2)}\right)^{\left[4-\left(i-i^{\prime}\right)\right]}\left(P_{\mathrm{Cu}}^{(2)}\right)^{\left(i-i^{\prime}\right)}\right]
\end{array}\right.
$$

In the Equations (32) to (35), $k$ and $K$ take their values, according to

$$
\begin{cases}k=0, K=i, & \text { if } i \leq 4 ; \\ k=i-4, K=i, & \text { if } 4<i \leq 8 \\ k=i-4, K=8, & \text { if } 8<i \leq 12 .\end{cases}
$$

The maximum order degree $\sigma_{\max }$ as function of composition $x_{\mathrm{Au}}$ :

For the stoichiometric alloy, due to $P_{\mathrm{Au}}^{(1)}=1$, $\sigma_{\max }=1$;

For the alloys with $x_{\mathrm{Au}}<v^{(1)}$, due to $P_{\mathrm{Au}}^{(2)}=0$, $\sigma_{\max }(x)=x_{\mathrm{Au}} / v^{(1)}$;

For the alloys with $x_{\mathrm{Au}}>v^{(1)}$, due to $P_{\mathrm{Au}}^{(1)}=1$, $\sigma_{\max }(x)=\left(1-x_{\mathrm{Au}}\right) /\left(1-v^{(1)}\right)$.

The methods for calculating $\omega_{i}^{(1)}$ and $\omega_{i}^{(2)}$ are listed in Supplementary Tables S4 and S5.

The configurational entropies of alloy and components:

$$
\left\{\begin{array}{l}
S^{c}(x, T)=k_{B} \ln \left(g\left(x_{i}^{\mathrm{Au}}, x_{i}^{\mathrm{Cu}}\right)\right)=x_{\mathrm{Au}} S^{\mathrm{Au} . c}(x, T)+x_{\mathrm{Cu}} S^{\mathrm{Cu} . c}(x, T) \\
S^{\mathrm{Au} . c}=-\frac{R}{x_{\mathrm{Au}}}\left\{\left(\sum_{i=0}^{I} x_{i}^{\mathrm{Au}(1)}(x, T)\right) \ln \left(\sum_{i=0}^{I}\left(P_{\mathrm{Au}}^{(1)} \omega_{i}^{(1)}\right)\right)+\left(\sum_{i=0}^{I} x_{i}^{\mathrm{Au}(2)}(x, T)\right) \ln \left(\sum_{i=0}^{I}\left(P_{\mathrm{Au}}^{(2)} \omega_{i}^{(2)}\right)\right)\right\} \\
S^{\mathrm{Cu} . c}=-\frac{R}{x_{\mathrm{Cu}}}\left\{\left(\sum_{i=0}^{I} x_{i}^{\mathrm{Cu}(1)}(x, T)\right) \ln \left(\sum_{i=0}^{I}\left(P_{\mathrm{Cu}}^{(1)} \omega_{i}^{(1)}\right)\right)+\left(\sum_{i=0}^{I} x_{i}^{\mathrm{Cu}(2)}(x, T)\right) \ln \left(\sum_{i=0}^{I}\left(P_{\mathrm{Cu}}^{(2)} \omega_{i}^{(2)}\right)\right)\right\}
\end{array}\right.
$$


Table S4. The methods for calculating the probability $\omega_{i}^{(1)}$ of coordinative cluster $[(I-i) \mathrm{Au}, i \mathrm{Cu}]$ surrounding the (1)sublattice point in AuCu-type order alloys.

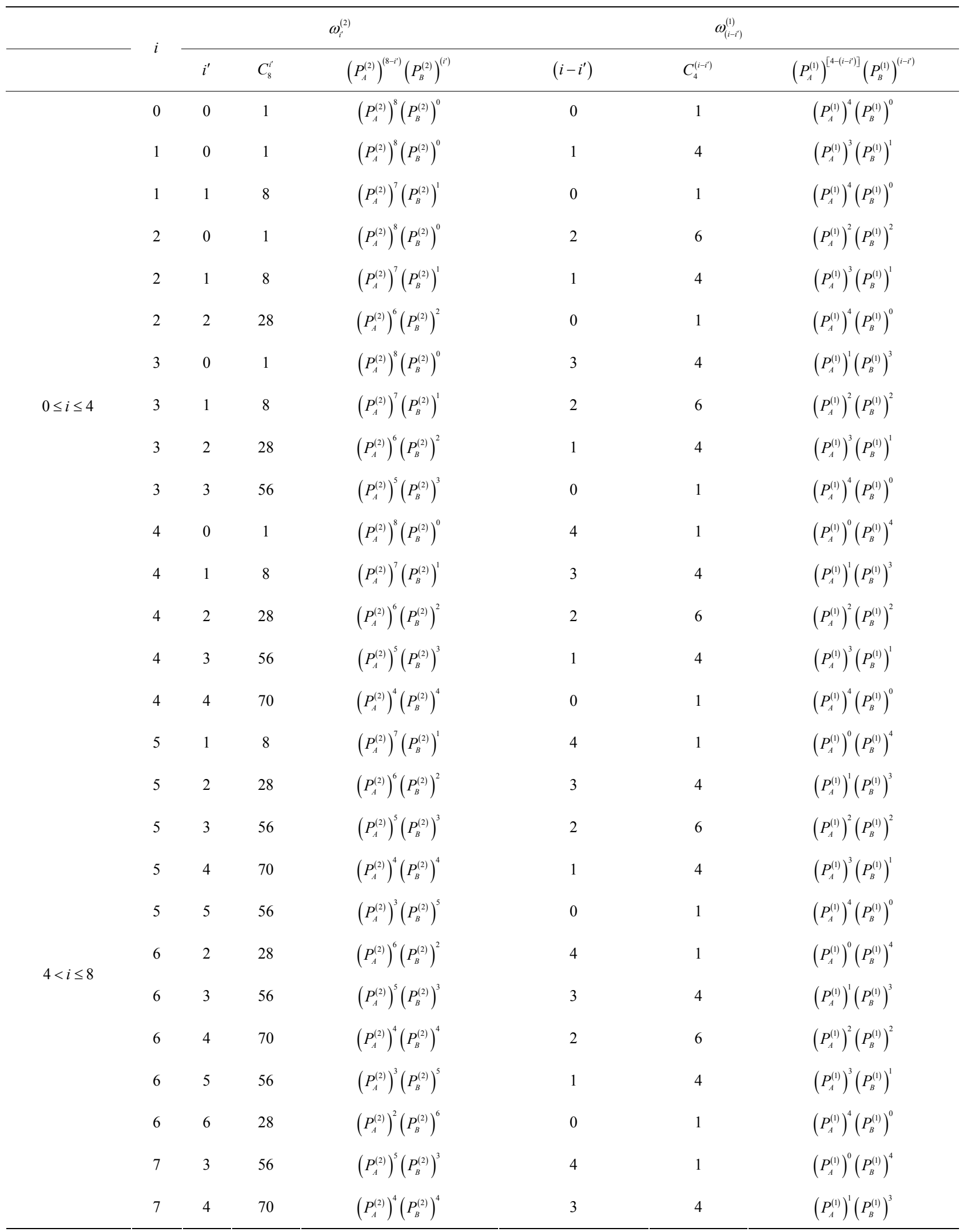




\begin{tabular}{|c|c|c|c|c|c|c|c|}
\hline & 7 & 5 & 56 & $\left(P_{A}^{(2)}\right)^{3}\left(P_{B}^{(2)}\right)^{5}$ & 2 & 6 & $\left(P_{A}^{(1)}\right)^{2}\left(P_{B}^{(1)}\right)^{2}$ \\
\hline & 7 & 6 & 28 & $\left(P_{A}^{(2)}\right)^{2}\left(P_{B}^{(2)}\right)^{6}$ & 1 & 4 & $\left(P_{A}^{(1)}\right)^{3}\left(P_{B}^{(1)}\right)^{1}$ \\
\hline & 7 & 7 & 8 & $\left(P_{A}^{(2)}\right)^{1}\left(P_{B}^{(2)}\right)^{7}$ & 0 & 1 & $\left(P_{A}^{(1)}\right)^{4}\left(P_{B}^{(l)}\right)^{0}$ \\
\hline & 8 & 4 & 70 & $\left(P_{A}^{(2)}\right)^{4}\left(P_{B}^{(2)}\right)^{4}$ & 4 & 1 & $\left(P_{A}^{(1)}\right)^{0}\left(P_{B}^{(1)}\right)^{4}$ \\
\hline & 8 & 5 & 56 & $\left(P_{A}^{(2)}\right)^{3}\left(P_{B}^{(2)}\right)^{5}$ & 3 & 4 & $\left(P_{A}^{(i)}\right)^{1}\left(P_{B}^{(i)}\right)^{3}$ \\
\hline & 8 & 6 & 28 & $\left(P_{A}^{(2)}\right)^{2}\left(P_{B}^{(2)}\right)^{6}$ & 2 & 6 & $\left(P_{A}^{(1)}\right)^{2}\left(P_{B}^{(1)}\right)^{2}$ \\
\hline & 8 & 7 & 8 & $\left(P_{A}^{(2)}\right)^{1}\left(P_{B}^{(2)}\right)^{7}$ & 1 & 4 & $\left(P_{A}^{(1)}\right)^{3}\left(P_{B}^{(1)}\right)^{1}$ \\
\hline & 8 & 8 & 1 & $\left(P_{A}^{(2)}\right)^{0}\left(P_{B}^{(2)}\right)^{8}$ & 0 & 1 & $\left(P_{A}^{(1)}\right)^{4}\left(P_{B}^{(1)}\right)^{0}$ \\
\hline & 9 & 5 & 56 & $\left(P_{A}^{(2)}\right)^{3}\left(P_{B}^{(2)}\right)^{5}$ & 4 & 1 & $\left(P_{A}^{(1)}\right)^{0}\left(P_{B}^{(i)}\right)^{4}$ \\
\hline & 9 & 6 & 28 & $\left(P_{A}^{(2)}\right)^{2}\left(P_{B}^{(2)}\right)^{6}$ & 3 & 4 & $\left(P_{A}^{(1)}\right)^{1}\left(P_{B}^{(1)}\right)^{3}$ \\
\hline & 9 & 7 & 8 & $\left(P_{A}^{(2)}\right)^{1}\left(P_{B}^{(2)}\right)^{7}$ & 2 & 6 & $\left(P_{A}^{(1)}\right)^{2}\left(P_{B}^{(1)}\right)^{2}$ \\
\hline & 9 & 8 & 1 & $\left(P_{A}^{(2)}\right)^{0}\left(P_{B}^{(2)}\right)^{8}$ & 1 & 4 & $\left(P_{A}^{(1)}\right)^{3}\left(P_{B}^{(1)}\right)^{1}$ \\
\hline 8 & 10 & 6 & 28 & $\left(P_{A}^{(2)}\right)^{2}\left(P_{B}^{(2)}\right)^{6}$ & 4 & 1 & $\left(P_{A}^{(1)}\right)^{0}\left(P_{B}^{(1)}\right)^{4}$ \\
\hline $0<1=12$ & 10 & 7 & 8 & $\left(P_{A}^{(2)}\right)^{1}\left(P_{B}^{(2)}\right)^{7}$ & 3 & 4 & $\left(P_{A}^{(1)}\right)^{1}\left(P_{B}^{(1)}\right)^{3}$ \\
\hline & 10 & 8 & 1 & $\left(P_{A}^{(2)}\right)^{0}\left(P_{B}^{(2)}\right)^{8}$ & 2 & 6 & $\left(P_{A}^{(1)}\right)^{2}\left(P_{B}^{(1)}\right)^{2}$ \\
\hline & 11 & 7 & 8 & $\left(P_{A}^{(2)}\right)^{1}\left(P_{B}^{(2)}\right)^{7}$ & 4 & 1 & $\left(P_{A}^{(1)}\right)^{0}\left(P_{B}^{(1)}\right)^{4}$ \\
\hline & 11 & 8 & 1 & $\left(P_{A}^{(2)}\right)^{0}\left(P_{B}^{(2)}\right)^{8}$ & 3 & 4 & $\left(P_{A}^{(1)}\right)^{1}\left(P_{B}^{(1)}\right)^{3}$ \\
\hline & 12 & 8 & 1 & $\left(P_{A}^{(2)}\right)^{0}\left(P_{B}^{(2)}\right)^{8}$ & 4 & 1 & $\left(P_{A}^{(1)}\right)^{0}\left(P_{B}^{(1)}\right)^{4}$ \\
\hline
\end{tabular}

The mole potential energies of the alloy and components:

$$
\left\{\begin{array}{l}
E(x, T)=x_{\mathrm{Au}} E^{\mathrm{Au}}(x, T)+x_{\mathrm{Cu}} E^{\mathrm{Cu}}(x, T) \\
E^{\mathrm{Au}}(x, T)=\left(1 / x_{\mathrm{Au}}\right) \sum_{i=0}^{I=12} x_{i}^{\mathrm{Au}}(x, T) E_{i}^{\mathrm{Au}}(0) \\
E^{\mathrm{Cu}}(x, T)=\left(1 / x_{\mathrm{Cu}}\right) \sum_{i=0}^{I=12} x_{i}^{\mathrm{Cu}}(x, T) E_{i}^{\mathrm{Cu}}(0)
\end{array}\right.
$$

The Debye vibration energies of alloy and components:

$$
\left\{\begin{array}{l}
U^{D}(x, T)=x_{\mathrm{Au}} U^{\mathrm{Au} . D}(x, T)+x_{\mathrm{Cu}} X^{\mathrm{Cu} . D}(x, T) \\
U^{\mathrm{Au} . D}(x, T)=\left(1 / x_{\mathrm{Au}}\right) \sum_{i=0}^{I=12} x_{i}^{\mathrm{Au}}(x, T) \int_{0}^{T} C_{p, i}^{\mathrm{Au} . D}(T) \mathrm{d} T(40) \\
U^{\mathrm{Cu} . D}(x, T)=\left(1 / x_{\mathrm{Cu}}\right) \sum_{i=0}^{I=12} x_{i}^{\mathrm{Cu}}(x, T) \int_{0}^{T} C_{p, i}^{\mathrm{Cu} . D}(T) \mathrm{d} T
\end{array}\right.
$$

The attaching vibration energies of alloy and components:

$$
\left\{\begin{array}{l}
U^{E}(x, T)=x_{\mathrm{Au}} U^{\mathrm{Au} . E}(x, T)+x_{\mathrm{Cu}} X^{\mathrm{Cu} . E}(x, T) \\
U^{\mathrm{Au} . E}(x, T)=\left(1 / x_{\mathrm{Au}}\right) \sum_{i=0}^{I=12} x_{i}^{\mathrm{Au}}(x, T) \int_{0}^{T} C_{p, i}^{\mathrm{Au} . E}(T) \mathrm{d} T \\
U^{\mathrm{Cu} . E}(x, T)=\left(1 / x_{\mathrm{Cu}}\right) \sum_{i=0}^{I=12} x_{i}^{\mathrm{Cu}}(x, T) \int_{0}^{T} C_{p, i}^{\mathrm{Cu} . E}(T) \mathrm{d} T
\end{array}\right.
$$

The generalized vibration energies of the alloy and components:

$$
\left\{\begin{array}{l}
U^{v}(x, T)=x_{\mathrm{Au}} U^{\mathrm{Au} . v}(x, T)+x_{\mathrm{Cu}} U^{\mathrm{Cu} . v}(x, T) \\
U^{\mathrm{Au} . v}(x, T)=\left(1 / x_{\mathrm{Au}}\right) \sum_{i=0}^{I=12} x_{i}^{\mathrm{Au}}(x, T) U_{i}^{\mathrm{Au} . v}(T) \\
U^{\text {Cu.v }}(x, T)=\left(1 / x_{\mathrm{Cu}}\right) \sum_{i=0}^{I=12} x_{i}^{\mathrm{Cu}}(x, T) U_{i}^{\text {Cu.v }}(T)
\end{array}\right.
$$


Table S5. The methods for calculating the probability $\omega_{i}^{(2)}$ of coordinative cluster $[(I-i) \mathrm{Au}, i \mathrm{Cu}]$ surrounding the (2)sublattice point in AuCu-type order alloys.

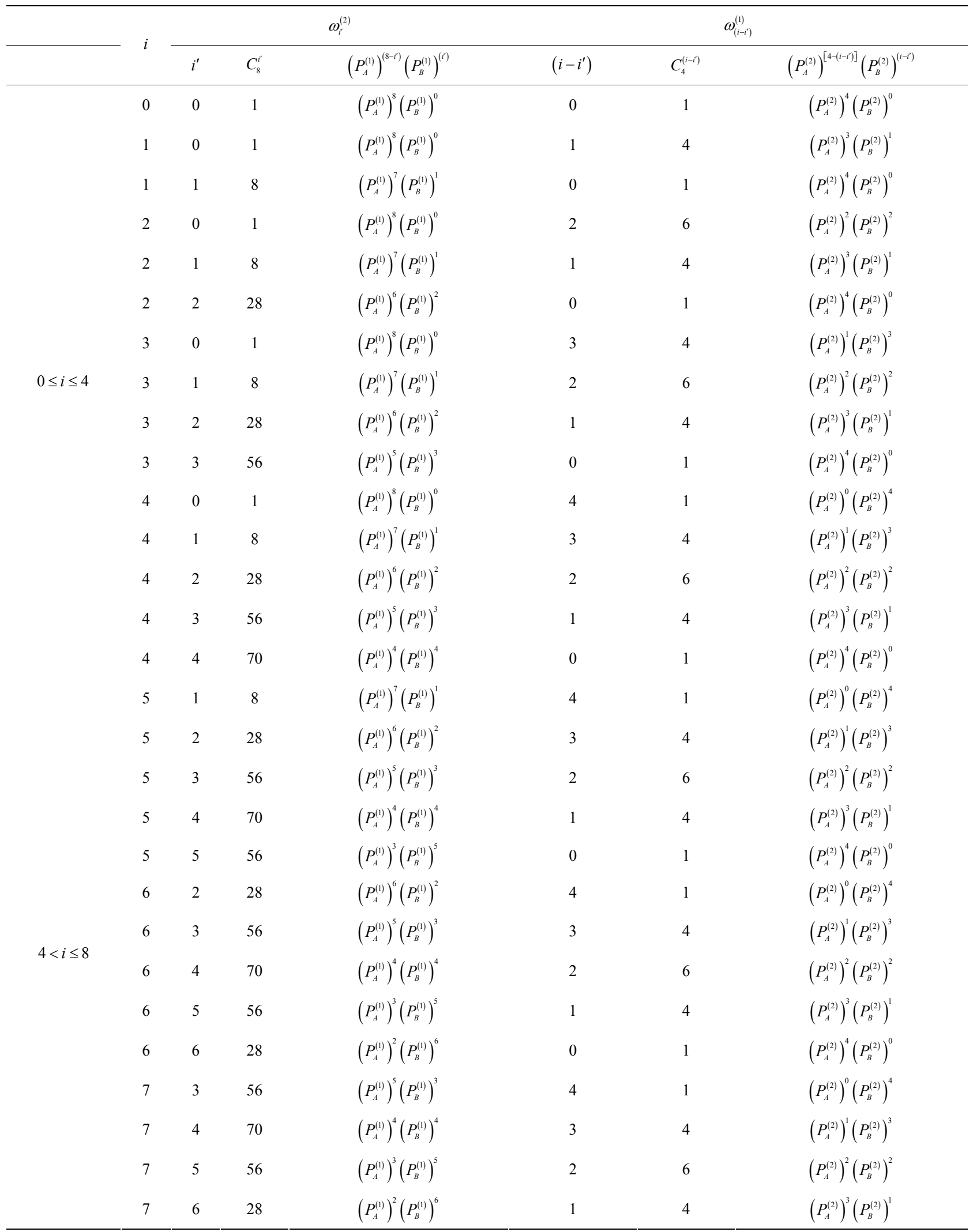




\begin{tabular}{ccccccl}
\hline 7 & 7 & 8 & $\left(P_{A}^{(1)}\right)^{1}\left(P_{B}^{(1)}\right)^{7}$ & 0 & 1 & $\left(P_{A}^{(2)}\right)^{4}\left(P_{B}^{(2)}\right)^{0}$ \\
8 & 4 & 70 & $\left(P_{A}^{(1)}\right)^{4}\left(P_{B}^{(1)}\right)^{4}$ & 4 & 1 & $\left(P_{A}^{(2)}\right)^{0}\left(P_{B}^{(2)}\right)^{4}$ \\
8 & 5 & 56 & $\left(P_{A}^{(1)}\right)^{3}\left(P_{B}^{(1)}\right)^{5}$ & 3 & 4 & $\left(P_{A}^{(2)}\right)^{1}\left(P_{B}^{(2)}\right)^{3}$ \\
8 & 6 & 28 & $\left(P_{A}^{(1)}\right)^{2}\left(P_{B}^{(1)}\right)^{6}$ & 2 & 6 & $\left(P_{A}^{(2)}\right)^{2}\left(P_{B}^{(2)}\right)^{2}$ \\
8 & 7 & 8 & $\left(P_{A}^{(1)}\right)^{1}\left(P_{B}^{(1)}\right)^{7}$ & 1 & 4 & $\left(P_{A}^{(2)}\right)^{3}\left(P_{B}^{(2)}\right)^{1}$ \\
8 & 8 & 1 & $\left(P_{A}^{(2)}\right)^{0}\left(P_{B}^{(2)}\right)^{8}$ & 0 & 1 & $\left(P_{A}^{(2)}\right)^{4}\left(P_{B}^{(2)}\right)^{0}$ \\
9 & 5 & 56 & $\left(P_{A}^{(1)}\right)^{3}\left(P_{B}^{(1)}\right)^{5}$ & 4 & 1 & $\left(P_{A}^{(2)}\right)^{1}\left(P_{B}^{(2)}\right)^{3}$ \\
9 & 6 & 28 & $\left(P_{A}^{(1)}\right)^{2}\left(P_{B}^{(1)}\right)^{6}$ & 3 & 4 & $\left(P_{A}^{(2)}\right)^{2}\left(P_{B}^{(2)}\right)^{2}$ \\
$9<i \leq 12$ & 7 & 8 & $\left(P_{A}^{(1)}\right)^{1}\left(P_{B}^{(1)}\right)^{7}$ & 2 & 6 & $\left(P_{A}^{(2)}\right)^{3}\left(P_{B}^{(2)}\right)^{1}$ \\
9 & 8 & 1 & $\left(P_{A}^{(2)}\right)^{0}\left(P_{B}^{(2)}\right)^{8}$ & 1 & 4 & $\left(P_{A}^{(2)}\right)^{0}\left(P_{B}^{(2)}\right)^{4}$ \\
10 & 6 & 28 & $\left(P_{A}^{(1)}\right)^{2}\left(P_{B}^{(1)}\right)^{6}$ & 4 & 1 & $\left(P_{A}^{(2)}\right)^{1}\left(P_{B}^{(2)}\right)^{3}$ \\
10 & 7 & 8 & $\left(P_{A}^{(1)}\right)^{1}\left(P_{B}^{(1)}\right)^{7}$ & 3 & 4 & $\left(P_{A}^{(2)}\right)^{2}\left(P_{B}^{(2)}\right)^{2}$ \\
10 & 8 & 1 & $\left(P_{A}^{(2)}\right)^{0}\left(P_{B}^{(2)}\right)^{8}$ & 2 & 6 & $\left(P_{A}^{(2)}\right)^{0}\left(P_{B}^{(2)}\right)^{4}$ \\
11 & 7 & 8 & $\left(P_{A}^{(1)}\right)^{1}\left(P_{B}^{(1)}\right)^{7}$ & 4 & 1 & $\left(P_{A}^{(2)}\right)^{1}\left(P_{B}^{(2)}\right)^{3}$ \\
11 & 8 & 1 & $\left(P_{A}^{(2)}\right)^{0}\left(P_{B}^{(2)}\right)^{8}$ & 3 & 4 & $\left(P_{A}^{(2)}\right)^{0}\left(P_{B}^{(2)}\right)^{4}$ \\
12 & 8 & 1 & $\left(P_{A}^{(2)}\right)^{0}\left(P_{B}^{(2)}\right)^{8}$ & 4 & 1 & \\
\hline
\end{tabular}

The Debye vibration entropies of the alloy and components:

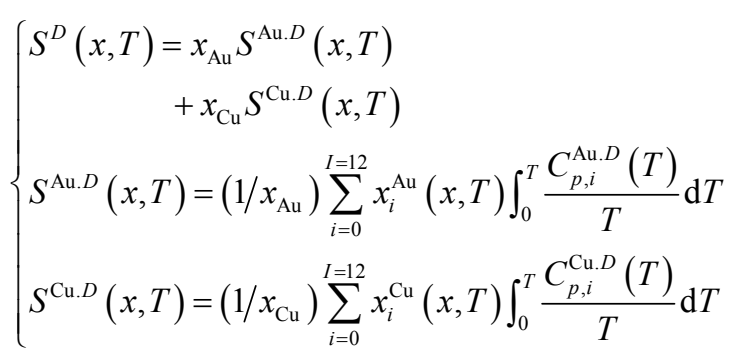

The attaching vibration entropies of the alloy and components:

$$
\left\{\begin{aligned}
& S^{E}(x, T)=x_{\mathrm{Au}} S^{\mathrm{Au} . E}(x, T) \\
&+x_{\mathrm{Cu}} S^{\mathrm{Cu} . E}(x, T) \\
& S^{\mathrm{Au} . E}(x, T)=\left(1 / x_{\mathrm{Au}}\right) \sum_{i=0}^{I=12} x_{i}^{\mathrm{Au}}(x, T) \int_{0}^{T} \frac{C_{p, i}^{\mathrm{Au} . E}(T)}{T} \mathrm{~d} T \\
& S^{\mathrm{Cu} . E}(x, T)=\left(1 / x_{\mathrm{Cu}}\right) \sum_{i=0}^{I=12} x_{i}^{\mathrm{Cu}}(x, T) \int_{0}^{T} \frac{C_{p, i}^{\mathrm{Cu} . E}(T)}{T} \mathrm{~d} T
\end{aligned}\right.
$$

The generalized vibration entropies of the alloy and components:

$$
\left\{\begin{array}{l}
S^{v}(x, T)=x_{\mathrm{Au}} S^{\mathrm{Au} . v}(x, T)+x_{\mathrm{Cu}} S^{\mathrm{Cu} . v}(x, T) \\
S^{\mathrm{Au} . v}(x, T)=\left(1 / x_{\mathrm{Au}}\right) \sum_{i=0}^{I=12} x_{i}^{\mathrm{Au}}(x, T) S_{i}^{\mathrm{Au} . v}(T) \\
S^{\mathrm{Cu} . v}(x, T)=\left(1 / x_{\mathrm{Cu}}\right) \sum_{i=0}^{I=12} x_{i}^{\mathrm{Cu}}(x, T) S_{i}^{\mathrm{Cu} \cdot v}(T)
\end{array}\right.
$$

The generalized vibration free energies of the alloy and components:

$$
\left\{\begin{array}{l}
X^{v}(x, T)=x_{\mathrm{Au}} X^{\mathrm{Au} . v}(x, T)+x_{\mathrm{Cu}} X^{\mathrm{Cu} . v}(x, T) \\
X^{\mathrm{Au} . v}(x, T)=\left(1 / x_{\mathrm{Au}}\right) \sum_{i=0}^{I=12} x_{i}^{\mathrm{Au}}(x, T) X_{i}^{\mathrm{Au} . v}(T) \\
X^{\mathrm{Cu} . v}(x, T)=\left(1 / x_{\mathrm{Cu}}\right) \sum_{i=0}^{I=12} x_{i}^{\mathrm{Cu}}(x, T) X_{i}^{\mathrm{Cu} . v}(T)
\end{array}\right.
$$

The enthalpies of the alloy and components:

$$
\left\{\begin{array}{l}
H(x, T)=x_{\mathrm{Au}} H^{\mathrm{Au}}(x, T)+x_{\mathrm{Cu}} H^{\mathrm{Cu}}(x, T) \\
H^{\mathrm{Au}}(x, T)=\left(1 / x_{\mathrm{Au}}\right) \sum_{i=0}^{I=12} x_{i}^{\mathrm{Au}}(x, T)\left(E_{i}^{\mathrm{Au}}(0)+U_{i}^{\mathrm{Au} \cdot v}(T)\right) \\
H^{\mathrm{Cu}}(x, T)=\left(1 / x_{\mathrm{Cu}}\right) \sum_{i=0}^{I=12} x_{i}^{\mathrm{Cu}}(x, T)\left(E_{i}^{\mathrm{Cu}}(0)+U_{i}^{\mathrm{Cu} \cdot v}(T)\right)
\end{array}\right.
$$


The characteristic Gibbs energies of the alloy and components:

$$
\left\{\begin{array}{l}
G^{*}(x, T)=x_{\mathrm{Au}} G^{* \mathrm{Au}}(x, T)+x_{\mathrm{Cu}} G^{* \mathrm{Cu}}(x, T) \\
G^{* \mathrm{Au}}(x, T)=\left(1 / x_{\mathrm{Au}}\right) \sum_{i=0}^{I=12} x_{i}^{\mathrm{Au}}(x, T) G_{i}^{\mathrm{Au}}(T) \\
G^{* \mathrm{Cu}}(x, T)=\left(1 / x_{\mathrm{Cu}}\right) \sum_{i=0}^{I=12} x_{i}^{\mathrm{Cu}}(x, T) G_{i}^{\mathrm{Cu}}(T)
\end{array}\right.
$$

The Gibbs energies of the alloy and components:

$$
\left\{\begin{array}{l}
G(x, T)=x_{\mathrm{Au}} G^{\mathrm{Au}}(x, T)+x_{\mathrm{Cu}} G^{\mathrm{Cu}}(x, T) \\
G^{\mathrm{Au}}(x, T)=\left(1 / x_{\mathrm{Au}}\right)\left(G^{* \mathrm{Au}}(x, T)-T S^{\mathrm{Au} . c}(x, T)\right) \\
G^{\mathrm{Cu}}(x, T)=\left(1 / x_{\mathrm{Cu}}\right)\left(G^{*}{ }^{* \mathrm{Cu}}(x, T)-T S^{\mathrm{Cu} . c}(x, T)\right)
\end{array}\right.
$$

The mixed heat capacity of the alloy:

$$
\left\{\begin{aligned}
\Delta C_{p}^{m}(x, T)= & \Delta C_{p}^{m . v}(x, T)+\Delta C_{p}^{m . s}(x, T) \\
\Delta C_{p}^{m, v}(x, T)= & \sum_{i=0}^{I} x_{i}^{\mathrm{Au}}(x, T)\left(C_{p, i}^{\mathrm{Au} . v}(T)-C_{p, 0}^{\mathrm{Au} . v}(T)\right) \\
& +\sum_{i=0}^{I} x_{i}^{\mathrm{Cu}}(x, T)\left(C_{p, i}^{\mathrm{Cu} . v}(T)-C_{p, 12}^{\mathrm{Cu} . v}(T)\right) \\
\Delta C_{p}^{m . s}(x, T)= & \sum_{i=0}^{I} \frac{\partial x_{i}^{\mathrm{Au}}(x, T)}{\partial \sigma} \cdot \frac{\mathrm{d} \sigma}{\mathrm{d} T}\left(H_{i}^{\mathrm{Au}}(T)-H_{0}^{\mathrm{Au}}(T)\right) \\
& +\sum_{i=0}^{I} \frac{\partial x_{i}^{\mathrm{Cu}}(x, T)}{\partial \sigma} \cdot \frac{\mathrm{d} \sigma}{\mathrm{d} T}\left(H_{i}^{\mathrm{Cu}}(T)-H_{12}^{\mathrm{Cu}}(T)\right)
\end{aligned}\right.
$$

The activities of the components:

$$
\left\{\begin{array}{l}
a_{\mathrm{Au}}(x, T)=x_{\mathrm{Au}} \cdot \exp \left(\Delta G_{\mathrm{Au}}^{* m}(x, T) / R T\right) \\
a_{\mathrm{Cu}}(x, T)=x_{\mathrm{Cu}} \cdot \exp \left(\Delta G_{\mathrm{Cu}}^{* m}(x, T) / R T\right) \\
\Delta G^{* \mathrm{Au}}(x, T)=\left(1 / x_{\mathrm{Au}}\right) \sum_{i=0}^{I=12} x_{i}^{\mathrm{Au}}(x, T)\left(G_{i}^{\mathrm{Au}}(T)-G_{0}^{\mathrm{Au}}(T)\right) \\
\Delta G^{* \mathrm{Cu}}(x, T)=\left(1 / x_{\mathrm{Cu}}\right) \sum_{i=0}^{I=12} x_{i}^{\mathrm{Cu}}(x, T)\left(G_{i}^{\mathrm{Cu}}(T)-G_{I}^{\mathrm{Cu}}(T)\right)
\end{array}\right.
$$

The volumes of the alloy and components:

$$
\left\{\begin{array}{l}
v(x, T)=x_{\mathrm{Au}} v^{\mathrm{Au}}(x, T)+x_{\mathrm{Cu}} v^{\mathrm{Cu}}(x, T) \\
v^{\mathrm{Au}}(x, T)=\left(1 / x_{\mathrm{Au}}\right) \sum_{i=0}^{I=12} x_{i}^{\mathrm{Au}}(x, T) v_{i}^{\mathrm{Au}}(T) \\
E^{\mathrm{Cu}}(x, T)=\left(1 / x_{\mathrm{Cu}}\right) \sum_{i=0}^{I=12} x_{i}^{\mathrm{Cu}}(x, T) v_{i}^{\mathrm{Cu}}(T)
\end{array}\right.
$$

The mixed volume thermal expansion coefficient of the alloy:

$$
\left\{\begin{array}{l}
\Delta \beta^{m}(x, T)=\Delta \beta^{m . v}(x, T)+\Delta \beta^{m . s}(x, T) \\
\Delta \beta^{m . v}(x, T)=\sum_{i=0}^{I} x_{i}^{\mathrm{Au}}(x, T)\left(\beta_{i}^{\mathrm{Au} . v}(T)-\beta_{0}^{\mathrm{Au} . v}(T)\right)+\sum_{i=0}^{I} x_{i}^{\mathrm{Cu}}(x, T)\left(\beta_{i}^{\mathrm{Cu} . v}(T)-\beta_{12}^{\mathrm{Cu} . v}(T)\right) \\
\Delta \beta^{m . s}(x, T)=\sum_{i=0}^{I}\left(\frac{1}{v_{i}^{\mathrm{Au}}(T)}\right) \frac{\partial x_{i}^{\mathrm{Au}}(x, T)}{\partial \sigma} \cdot \frac{\mathrm{d} \sigma}{\mathrm{d} T}\left(v_{i}^{\mathrm{Au}}(T)-v_{0}^{\mathrm{Au}}(T)\right)+\sum_{i=0}^{I}\left(\frac{1}{v_{i}^{\mathrm{Cu}}(T)}\right) \frac{\partial x_{i}^{\mathrm{Cu}}(x, T)}{\partial \sigma} \cdot \frac{\mathrm{d} \sigma}{\mathrm{d} T}\left(v_{i}^{\mathrm{Cu}}(T)-v_{12}^{\mathrm{Cu}}(T)\right)
\end{array}\right.
$$

It should be emphasized that the new $\Omega(x, T)$-function can be used to describe both long-distance order and short-distance order states of alloy phases, because our model includes the sublattice model and coordinative model (Equation (32)), and that, the thermodynamic properties of alloy components need no representatives by the partial molar properties. We have proved that the partial molar properties cannot represent the average properties of the corresponding components [20].

\section{EHNP Diagrams of Thermodynamic Properties of AuCu-type Sublattice Alloy System}

According to three-dimension $\Delta G^{m}-x-T$ and $\sigma-x-T$ EHNP diagrams, we have obtained other $q-x-T$ EHNP diagrams of the AuCu-type sublattice system in Supplementary Figure S6.

It should be emphasized that from each three-dimension $q-x-T$ EHNP diagram we can obtain isocompo- 

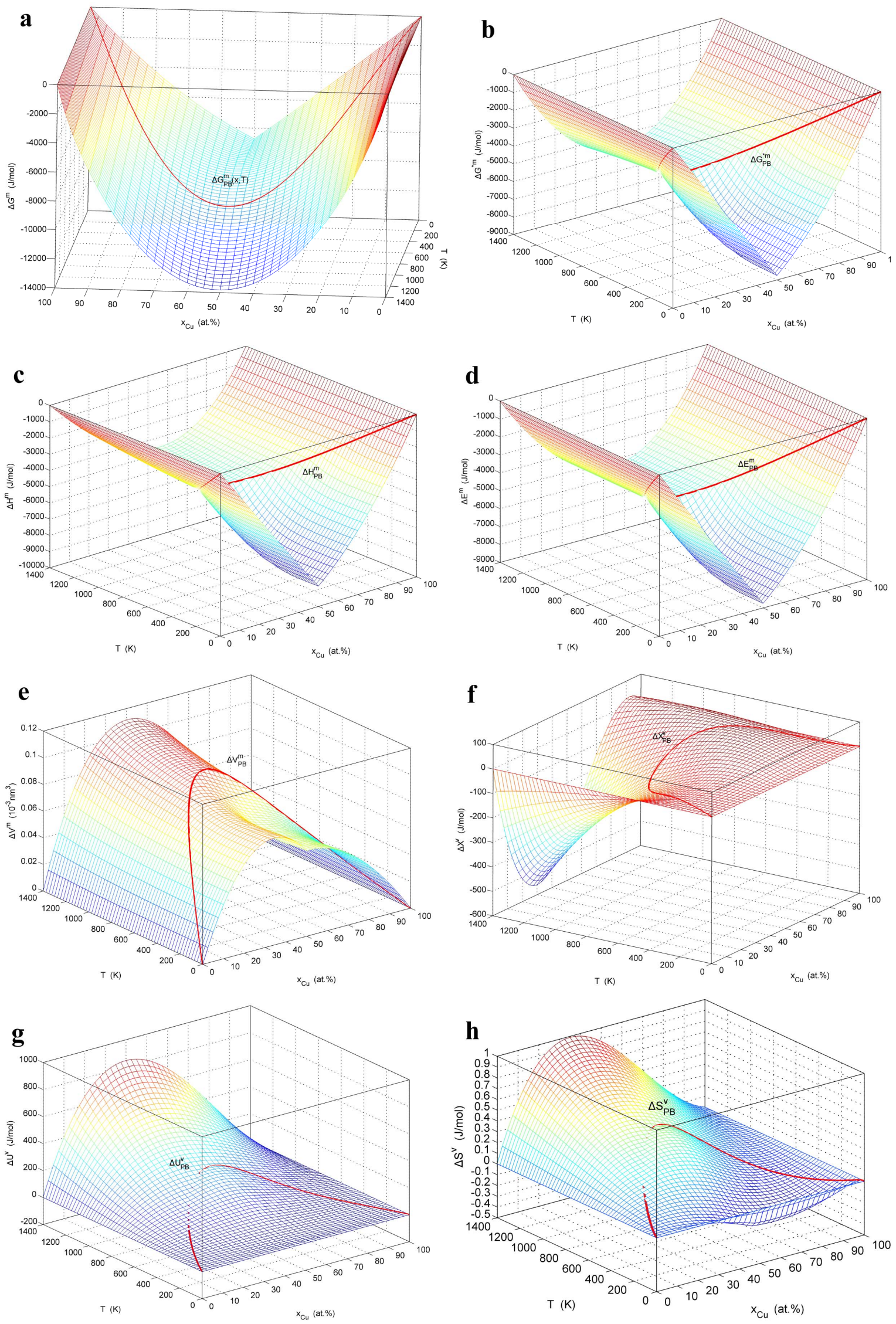

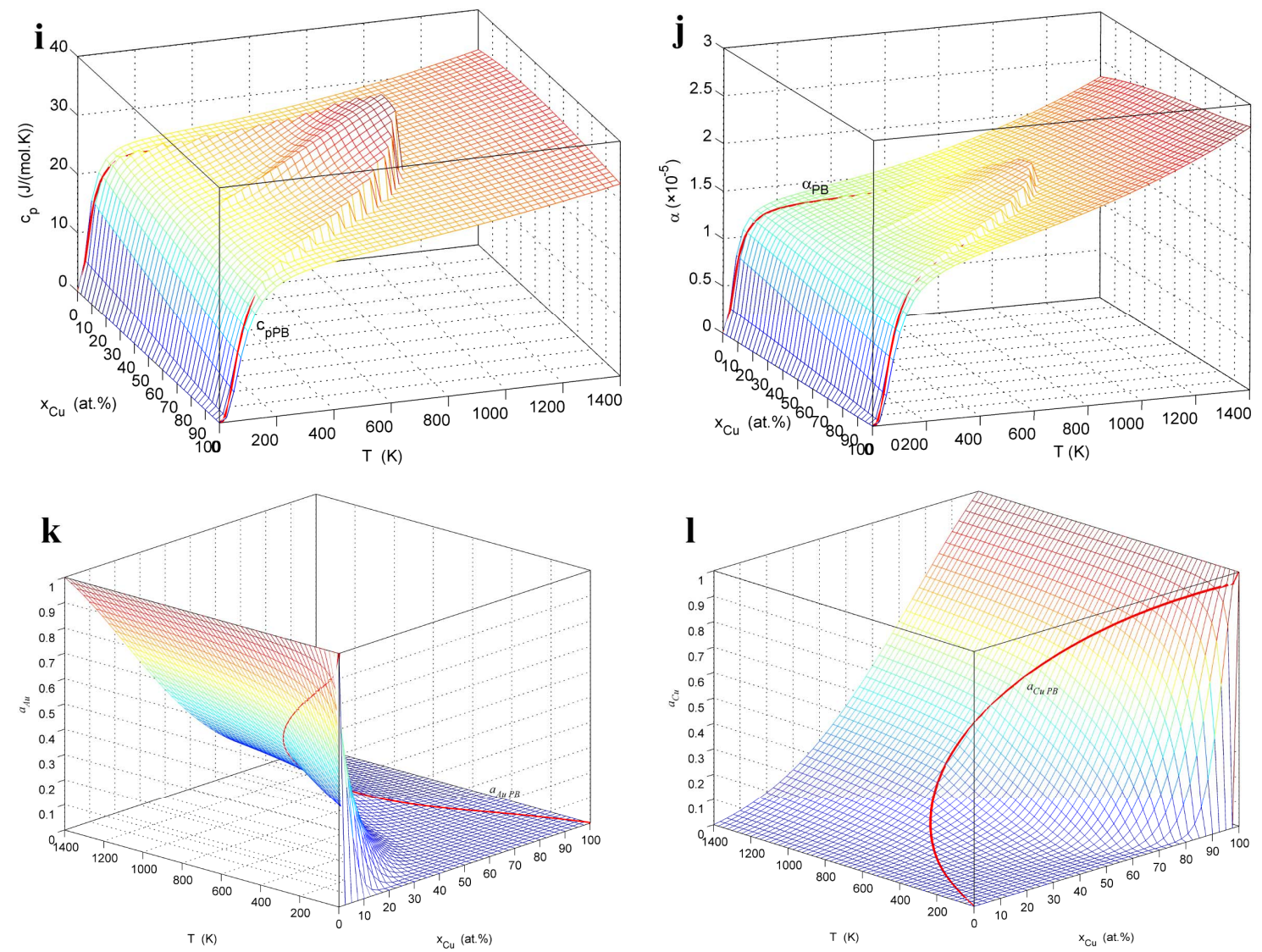

Figure S6. The $q-x-T$ EHNP diagrams of the AuCu-type sublattice system. a) Mixed Gibbs energy $\Delta G^{m}-x-T$ three-dimension EHNP diagram; b) Mixed characteristic Gibbs energy $\Delta G^{* m}-x-T$ three-dimension EHNP diagram, without including configuration entropy; c) Mixed enthalpy $\Delta H^{m}-x-T$ three-dimension EHNP diagram; d) Mixed potential energy $\Delta E^{m}-x-T$ three-dimension EHNP diagram, without including variations in AG-potential energies with temperatures; e) Mixed volume $\Delta V^{m}-x-T$ three-dimension EHNP diagram; f) Generalized mixed vibration free energy $\Delta X^{v}-x-T$ three-dimension EHNP diagram; g) Generalized mixed vibration energy $\Delta U^{v}-x-T$ three-dimension EHNP diagram, including variations in AG-potential energies with temperatures; h) Generalized mixed vibration entropy $\Delta S^{v}-x-T$ three-dimension EHNP diagram; i) Heat capacity $C_{p}^{m}-x-T$ three-dimension EHNP diagram; j) Thermal expansion coefficient $\alpha-x-T$ three-dimension EHNP diagram; k) $a_{\mathrm{Au}}-x-T$ three-dimension diagram; l) $a_{\mathrm{Cu}}-x-T$ three-dimension diagram.

sitional $q_{x}-T$, isoproperty $T_{q}-x$, and isothermal $q_{T}-x$ path phase diagrams. These diagrams are interconnected to form a big database about structures, properties and their variations with temperature of alloy systems. Therefore, the man's knowledge of relationships of structures, properties and environments for alloy systems has been changed from single causality to systematic correlativity. 